Provided for non-commercial research and education use. Not for reproduction, distribution or commercial use.

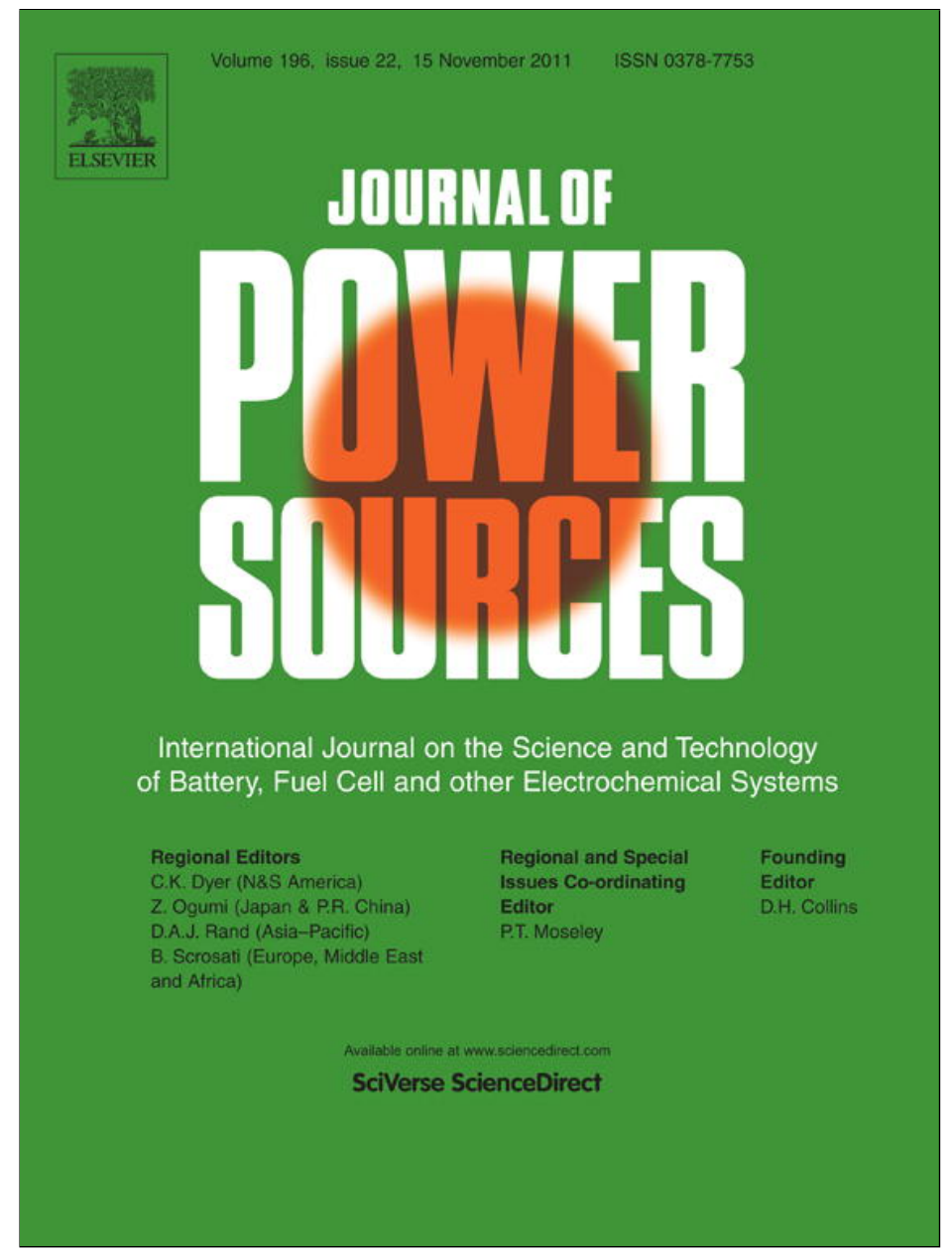

This article appeared in a journal published by Elsevier. The attached copy is furnished to the author for internal non-commercial research and education use, including for instruction at the authors institution and sharing with colleagues.

Other uses, including reproduction and distribution, or selling or licensing copies, or posting to personal, institutional or third party websites are prohibited.

In most cases authors are permitted to post their version of the article (e.g. in Word or Tex form) to their personal website or institutional repository. Authors requiring further information regarding Elsevier's archiving and manuscript policies are encouraged to visit:

http://www.elsevier.com/copyright 


\title{
On the proton conductivity of Nafion-Faujasite composite membranes for low temperature direct methanol fuel cells
}

\author{
Zhonghua Zhang ${ }^{\mathrm{a}}$, François Désilets ${ }^{\mathrm{a}, \mathrm{b}}$, Valeria Felice ${ }^{\mathrm{a}}$, Barbara Mecheri $^{\mathrm{c}}$, Silvia Licoccia ${ }^{\mathrm{c}}$, Ana C. Tavares $^{\mathrm{a}, *}$ \\ a Institut National de la Recherche Scientifique-Énergie, Matériaux et Télécommunications, 1650 Boulevard Lionel Boulet, Varennes, Québec, Canada J3X $1 S 2$ \\ b Département de génie chimique et biotechnologique, Université de Sherbrooke, 2500 Boulevard de l'Université, Sherbrooke, Québec, Canada J1K 2R1 \\ ' Department of Chemical Science and Technology \& NAST Centre, University of Rome Tor Vergata, Via della Ricerca Scientifica, 00133 Rome, Italy
}

\section{A R T I C L E I N F O}

\section{Article history:}

Received 9 May 2011

Received in revised form 1 July 2011

Accepted 5 July 2011

Available online 12 July 2011

\section{Keywords:}

Direct methanol fuel cells

Composite membrane

Faujasite zeolite

Nafion

Proton conductivity

States of water

\begin{abstract}
A B S T R A C T
Although zeolites are introduced to decrease methanol crossover of Nafion membranes for direct methanol fuel cells (DMFCs), little is known about the effect of their intrinsic properties and the interaction with the ionomer. In this work, Nafion-Faujasite composite membranes prepared by solution casting were characterized by extensive physicochemical and electrochemical techniques. Faujasite was found to undergo severe dealumination during the membrane activation, but its structure remained intact. The zeolite interacts with Nafion probably through hydrogen bonding between $\mathrm{Si}-\mathrm{OH}$ and $\mathrm{SO}_{3} \mathrm{H}$ groups, which combined with the increase of the water uptake and the water mobility, and the addition of a less conductive phase (the zeolite) leads to an optimum proton conductivity between 0.98 and 2 wt\% of zeolite. Hot pressing the membranes before their assembling with the electrodes enhanced the DMFC performance by reducing the methanol crossover and the serial resistance.
\end{abstract}

(C) 2011 Elsevier B.V. All rights reserved.

\section{Introduction}

Direct methanol fuel cells (DMFCs) are promising power sources for mobile and portable applications due to their high energy density, low pollutant emission, simple system design, and abundant fuel sources [1-3]. The bottlenecks restricting the commercialization of DMFCs are Pt-based catalysts [4] and perflurosulfonic acid membranes [5] which are too expensive to be used in large quantities. The current state-of-the-art membrane is still the Nafion ${ }^{\circledR}$ membrane (DuPont) which has excellent proton conductivity, mechanical strength, and thermal and chemical stability. However, serious methanol crossover through the Nafion membrane not only decreases the fuel utilization, but also leads to mixed potential on the cathode, thus the decreasing the overall performance of DMFCs [6-8]. Many types of inorganic fillers have been reported to decrease the methanol crossover of Nafion membrane. Although some improved electrochemical characteristics

\footnotetext{
* Corresponding author. Tel.: +1 450929 8947; fax: +1 4509298102.

E-mail addresses: zhangz@emt.inrs.ca (Z. Zhang),

Francois.Desilets@usherbrook.ca (F. Désilets), felice@emt.inrs.ca (V. Felice), barbara.mecheri@uniroma2.it (B. Mecheri), licoccia@uniroma2.it (S. Licoccia), tavares@emt.inrs.ca (A.C. Tavares).
}

have been reported, especially when intrinsically proton conducing fillers have been used, most of the composite membranes have lower proton conductivity than the pure Nafion membrane [9-19].

Zeolites are a class of crystalline aluminosilicates composed of interconnected $\mathrm{TO}_{4}$ tetrahedron $(\mathrm{T}=\mathrm{Si}, \mathrm{Al})[20,21]$ and contain cations electrostatically bound to the host framework to compensate the negative charge introduced by the $\mathrm{Al}(\mathrm{III})$. These cations can move freely along the diffusion paths formed by voids and channels in the zeolite structure, and are responsible for the ion conducting properties of zeolites [22].Zeolites are highly hydrophilic solids and have a high water sorption capacity because of the charged anionic framework and the extra-framework cations $[23,24]$ in addition to their open structure, high pore volume and surface area.

Zeolites' strong affinity to water, which acts as a vehicle for proton migration, and their sieving properties, have been the reasons for proposing zeolites as additives to Nafion membranes to reduce methanol permeability $[25,26]$, or as the electrolyte itself blended with a non conducting polymer binder in novel composite membranes [27-29].

Several works have been reported on Nafion-zeolite composite membranes, including reports on the incorporation of acid functionalized zeolites to improve the proton conductivity of the composite membrane [25,30-32] or to improve the dispersion of the zeolite particles, and studies on the effect of the zeolite particle 
size, the Si/Al ratio [33], or the solvent used in membrane fabrication. Some of these studies confirmed that zeolites can improve the performance of Nafion based DMFCs operating at temperature higher than $70^{\circ} \mathrm{C}$ and with $\mathrm{O}_{2}$ fed at the cathode, although the impact of the zeolite incorporation on the proton conductivity and methanol permeability of membranes varies between the reported works.

Zeolites undergo severe dealumination in acid medium which is the case of a hydrated Nafion membrane, or during the standard activation procedure used for Nafion membranes [34]. Dealumination causes variation of the $\mathrm{Si} / \mathrm{Al}$ ratio and changes the zeolites' surface chemistry and textural properties. These variations should be taken into account on the development of zeolite composite membranes. Most of the authors always refer to the nominal zeolite content, except in one paper [31] where the zeolite content was determined by TGA analysis after the activation procedure. In two works [33] it is not indicated whether the composite membranes were subjected, or not, to the activation procedure. Finally, none of the previous work deals with the action mechanism of the zeolites and its interaction with Nafion, which is essential for the development of zeolite-based composite membranes for DMFCs.

In the present work, we report the preparation and characterization of Nafion-Faujasite zeolite composite membranes for low temperature DMFCs. We comprehensively investigate zeolite dealumination, the interaction between Nafion and Faujasite zeolite, the hot pressing of the membranes and the impact on the morphology, composition, structure, ion exchange capacity, water uptake, states of water, and proton conductivity of the composite membranes. Faujasite-type zeolites have been chosen as fillers because of their large pore size, open three-dimensional pore system resulting in much faster intracrystalline diffusion rates compared to other zeolites [35,36]. Moreover, Faujasite zeolites are commercially available in a wide range of compositions. In particular, the Faujasite zeolite CBV780 ( $\mathrm{H}$ form) was used in this work because of its very high surface area $\left(823 \mathrm{~m}^{2} \mathrm{~g}^{-1}\right)$ which should facilitate the interaction with Nafion polymer, and of the very high Si/Al ratio $(=48.7)$ making them therefore more stable in acid environments than the other Al-rich Faujasites.

\section{Experimental}

\subsection{Membrane preparation}

Two series of composite membranes were prepared by casting a suspension formed by the desired amount of the CBV780 Faujasite zeolite powder (CBV780, Si $/ \mathrm{Al}$ molar $=48.7$, particle size ca. $1 \mu \mathrm{m}$, Zeolyst International, USA) dispersed into $5 \mathrm{wt} \%$ or $20 \mathrm{wt} \% \mathrm{com}-$ mercial Nafion ${ }^{\circledR}$ dispersions (DE521 and DE2021 Nafion ${ }^{\circledR}$ Polymer Dispersions, Ion Power Inc.). Isopropanol was added to the $20 \mathrm{wt} \%$ Nafion ${ }^{\circledR}$ dispersion (1.66 g of isopropanol for each $5 \mathrm{~g}$ of DE2021 dispersion). The suspensions were stirred for $30 \mathrm{~min}$ and sonicated for 30 additional minutes to disperse the zeolite uniformly and then poured into a glass Petri dish. The solvent was evaporated in an oven at $50^{\circ} \mathrm{C}$ for $5-6 \mathrm{~h}$, followed by a thermal treatment at $100^{\circ} \mathrm{C}$ overnight and at $140^{\circ} \mathrm{C}$ for 1 day. The membranes were peeled off by immersion in water. A third series of composite membranes was obtained by additionally hot pressing the membranes prepared with the DE2021 Nafion dispersion: the membranes protected by two Teflon sheets were placed for $1 \mathrm{~min}$ between the plates of a Carver press (model $3851-0$ ) heated at $140^{\circ} \mathrm{C}$ and then hot pressed under a pressure of 500 pound $\mathrm{cm}^{-2}$ for $40 \mathrm{~s}$. The nominal zeolite content in the composite membranes is $2,4,10,20$ and $40 \mathrm{wt} \%$, but membranes with the highest zeolite loadings could be prepared only from the DE2021 Nafion dispersion.
The two series of samples prepared from $5 \mathrm{wt} \%$ or $20 \mathrm{wt} \%$ Nafion ${ }^{\circledR}$ dispersions are labelled N5_n and N20_n where $n$ varies from 1 to 5 and is associated with nominal zeolite content from 2 to $40 \mathrm{wt} \%$. Hot pressed membranes are referred to as N20_n_HP.

All membranes were activated using the standard procedure for Nafion membranes. They were successively boiled for 1 hour in 3 vol\% $\mathrm{H}_{2} \mathrm{O}_{2}$ solution, DI water and $1.2 \mathrm{~mol} \mathrm{dm}^{-3} \mathrm{H}_{2} \mathrm{SO}_{4}$ solution. Finally, the membranes were stored in deionized water for further characterization.

\subsection{Thermal, morphological characterization and surface chemistry}

Thermogravimetric analysis (TGA) of the recast Nafion and composite membranes were conducted using a ThermoGravimetric/Differential Thermal Analyzer (TG/DTA200, Seiko Instrument, Inc.). The measurements were carried out under nitrogen flow, and the samples were conditioned at $25^{\circ} \mathrm{C}$ for $15 \mathrm{~min}$ and then heated to $650^{\circ} \mathrm{C}$ at a heating rate of $10^{\circ} \mathrm{C} \mathrm{min}-1$. Surface and cross-section micrographs of the membranes were obtained using JEOL JSM-6300F scanning electron microscope (SEM). A carbon film was sputter coated on the membranes using a carbon IF Filament unit prior to the SEM observations. The cross-sections of the composite membranes were obtained by fracturing the membranes in liquid nitrogen. X-ray photoelectron spectroscopy (XPS) analysis was performed with a VG Escalab 220i-XL equipped with $\mathrm{Mg}$ polychromatic twin source $\left(\mathrm{Mg} \mathrm{K} \mathrm{K}_{\alpha}=1253.6 \mathrm{eV}\right)$ operating at $15 \mathrm{kV}$ and $20 \mathrm{~mA}$. The signal was filtered with a hemispherical analyzer ( pass energy $=20 \mathrm{eV}$ ) and the detection was performed with a multi-channel detector. The base pressure inside the spectrometer during analysis was $4 \times 10^{-8} \mathrm{~Pa}$. The samples were kept overnight in the preparation chamber before being transferred to the analysis chamber. The $\mathrm{C}(1 \mathrm{~s})$ photoelectron line at $284.6 \mathrm{eV}$ was used as internal standard for the correction of the charging effect in all samples. Casa XPS software was used to analyze each core level spectrum and determine the element concentration.

\subsection{Water uptake and ion exchange capacity (IEC)}

For water uptake measurements, the membranes were immersed into DI water overnight at room temperature. Excess water was removed from the membrane surface with wipe paper and the membrane weighed (denoted as $m_{\mathrm{w}}$ ). The membranes were then dried at $80^{\circ} \mathrm{C}$ for $2 \mathrm{~h}$ in a vacuum oven and weighed (denoted as $m_{\mathrm{d}}$ ). The percentage of water uptake was calculated as follows:

Water uptake $(\%)=\frac{m_{\mathrm{w}}-m_{\mathrm{d}}}{m_{\mathrm{d}}} \times 100$

The IEC expressed as mmol of sulfonic acid groups for $1 \mathrm{~g}$ of dry polymer was determined through acid-base titration. The membranes were dried at $80^{\circ} \mathrm{C}$ for $2 \mathrm{~h}$ in a vacuum oven, weighed (denoted as $m_{\mathrm{d}}$ ), and then immersed overnight into a $0.1 \mathrm{M} \mathrm{NaCl}$ solution to exchange the protons with $\mathrm{Na}^{+}$ions. This solution was afterwards titrated with a $0.02 \mathrm{M} \mathrm{NaOH}$ solution until $\mathrm{pH}=7$. IEC was calculated according to the following equation.

IEC $\left(\mathrm{mmol} \mathrm{g}^{-1}\right)=\frac{V_{\mathrm{eq}} \cdot C_{\mathrm{NaOH}}}{m_{\mathrm{d}}}$

where $V_{\mathrm{eq}}$ is the equivalent volume of $\mathrm{NaOH}$ solution.

\subsection{Differential scanning calorimetry}

The fraction of freezable water in Nafion-zeolite composite membranes prepared from the DE2021 dispersion was determined from differential scanning calorimetry (DSC) measurements using a DSC 7 Perkin Elmer instrument. The samples were equilibrated in 
liquid water at $25^{\circ} \mathrm{C}$; then blotted with adsorbent paper and quickly sealed in aluminum DSC pans. In a typical run, $20 \mathrm{mg}$ of sample (2 membrane disks of $6 \mathrm{~mm}$ in diameter) was cooled from $25^{\circ} \mathrm{C}$ to $-50^{\circ} \mathrm{C}$, then heated from $-50^{\circ} \mathrm{C}$ to $10^{\circ} \mathrm{C}$ at $10^{\circ} \mathrm{C} \mathrm{min}^{-1}$, under $\mathrm{N}_{2}$ flow $\left(20 \mathrm{~mL} \mathrm{~min}^{-1}\right)$. The presented DSC data are the average values of quadruplicate analyses on different disks of the same sample.

\subsection{Proton conductivity}

Proton conductivity measurements were carried out on fully hydrated membranes at room temperature, and in both in-plane and through-plane (cross-section) directions. A Bekktech conductivity cell fixture with four Pt electrodes was used for the in-plane conductivity [37]. The membranes were soaked in water overnight before the measurements. The cell fixture was put inside a closed glass box with water in the bottom, and a water soaked filter paper was put on the top of the cell to keep the membranes fully hydrated. A four-electrode DC technique was applied, and a highimpedance digital voltmeter and a potentiostat/galvanostat (AMEL Instruments Model 2051) were used. The two external platinum electrodes were connected to the galvanostat and the two central platinum electrodes were connected to the digital voltmeter to measure the potential drop along the film section. The current between the external electrodes was varied between 0 and $15 \mathrm{~mA}$ and back to $0 \mathrm{~mA}$ by a step of $1 \mathrm{~mA}$, and the potential difference between the two inner Pt electrodes recorded. The slope on the $E-I$ plot corresponds to the membrane resistance, $R_{\text {mem }}$. A full cycle was always recorded, and the overlapping of the two straight lines confirmed that the membranes did not start to dry out during the measurements; the membranes' proton conductivity was calculated from Eq. (3):

$\sigma=\frac{1}{\rho}=\frac{l}{R_{\mathrm{mem}} A}$

where $l$ denotes the distance between the two inner Pt electrodes, $A$ is the product of the membrane width and thickness. The in-plane conductivity measurements were carried out on both faces of the membranes and the two values are reported.

Conductivity measurements through the membranes' crosssection were carried out in a four-compartment glass cell according to the procedure reported by Slade et al. [38]. A four-electrode DC technique was applied, and the two external platinum electrodes were connected to the galvanostat whereas the two central saturated calomel reference electrodes (SCE) were connected to a digital voltmeter. The cell was first filled with an electrolyte solution $\left(0.5 \mathrm{~mol} \mathrm{dm}^{-3} \mathrm{H}_{2} \mathrm{SO}_{4}\right)$, and the background resistance $\left(R_{\text {electrolyte }}\right)$ was determined. The current between the external electrodes was varied between 0 and $200 \mathrm{~mA}$ and back to $0 \mathrm{~mA}$ by a step of $20 \mathrm{~mA}$, and the potential difference between the other two reference electrodes recorded. Next, the resistance of the cell filled with the electrolyte and equipped with the membrane was measured. Three full cycles were always recorded. The membrane resistance $\left(R_{\mathrm{mem}}\right)$ was obtained by subtracting the background resistance $\left(R_{\text {electrolyte }}\right)$ from the total cell resistance. The membrane conductivity $(\sigma)$ was calculated by Eq. (3), where $l$ and $A$ represent the thickness and circular area $\left(0.79 \mathrm{~cm}^{2}\right)$ of membranes, respectively.

\subsection{Direct methanol fuel cell tests}

Two Nafion-zeolite composite membranes (N20_2 and N20_2HP) were tested in DMFC. The membranes were prepared from the DE2021 Nafion dispersion and contain $4 \mathrm{wt} \%$ of nominal zeolite. One of the membranes was subjected to the final hot pressing treatment before membrane activation in $\mathrm{H}_{2} \mathrm{O}_{2} / \mathrm{H}_{2} \mathrm{O} / \mathrm{H}_{2} \mathrm{SO}_{4}$ and assembling with electrodes. Both anode and cathode were purchased from Electrochem Inc.; the anode catalyst layer contains
$3 \mathrm{mg} \mathrm{cm}^{-2} \mathrm{PtRu}$ (from a $60 \mathrm{wt} \% \mathrm{PtRu} /$ Vulcan XC-72 catalyst) and the cathode catalyst layer contained $3 \mathrm{mg} \mathrm{cm}^{-2} \mathrm{Pt}$ (from a $60 \mathrm{wt} \%$ Pt/Vulcan XC-72 catalyst), and were coated with $1 \mathrm{mg} \mathrm{cm}^{-2}$ Nafion. The membrane electrodes assembly (MEA) were hot pressed at $140^{\circ} \mathrm{C}$ and installed in a fuel cell fixture of $5 \mathrm{~cm}^{2}$ active area (Fuel Cell Technologies). The single cells were connected to a fuel cell test station (model 850c from Scribner Associates) and equilibrated with the humidified gases at room temperature. For each MEA two cycles of galvanostatic polarizations were recorded between 25 and $80^{\circ} \mathrm{C}$ with $1 \mathrm{~mol} \mathrm{dm}^{-3}$ methanol solution fed to the anode chamber and with humidified air pre-heated at the same cell temperature fed to the cathode. Atmospheric pressure in the anode and cathode compartments was used for all experiments. The flow rates of methanol and air were 2.5 and $220 \mathrm{~mL} \mathrm{~min}^{-1}$, respectively. The MEAs performance improved during the first 2 days of operation and reached steady-state behavior. Only the data set recorded under steady-state conditions is presented.

\subsection{Dealumination and characterization of Faujasite zeolite}

To investigate whether dealumination of zeolite occurred during the pre-treatment of composite membranes, the zeolite powders were subjected to the same pre-treatment as the membranes. The zeolite powders were successively suspended for $1 \mathrm{~h}$ in the boiling $3 \mathrm{vol} \% \mathrm{H}_{2} \mathrm{O}_{2}$ solution, DI water and $1.2 \mathrm{~mol} \mathrm{dm}^{-3}$ $\mathrm{H}_{2} \mathrm{SO}_{4}$ solution, and then filtered and dried. The chemical composition of the parent and dealuminated zeolite was determined by Neutron Activation Analysis (NAA, at the Institute of Nuclear Engineering, École Polytechnique de Montreal). X-ray diffraction (XRD) was performed using a Bruker D8 Advance diffractometer equipped with a $\mathrm{Cu} \mathrm{Ka}(k=1.5405 \AA)$ as radiation source operating at $40 \mathrm{kV}$ and $40 \mathrm{~mA}$. The data was collected between $2^{\circ}$ and $40^{\circ}(2 \theta)$ in a step mode of $0.02^{\circ}$ and $1 \mathrm{~s}$ duration. The unit cell parameter, $a_{0}$, was calculated using EVA V14 software. Nitrogen adsorption measurements were carried out at $-196^{\circ} \mathrm{C}$ (Quantachrome Autosorb Automated Gas Sorption System, from Quantachrome Instruments). BET and Non Local-Density Functional theories were used for the determination of the surface area and the pore size distribution, respectively.

Electrochemical impedance spectroscopy (EIS) was used to measure the proton conductivity of the zeolites in a pellet form [39]. EIS spectra were recorded with a SI 1260 impedance/gain-phase analyzer (Solartron) controlled by a PC through a GPIB interface, and by applying a sinusoidal signal with amplitude of $10 \mathrm{mV}$ over the frequency range $1 \mathrm{~Hz}$ to $10 \mathrm{MHz}$. The pellets with a diameter of $7.2 \mathrm{~mm}$ were prepared by pressing ca. $50 \mathrm{mg}$ of zeolite powder under 1200 pounds for $1 \mathrm{~min}$ and then immersed into DI water for $48 \mathrm{~h}$. The pellets resistance, $R$, was obtained from the amplitude of the semi-circle on the complex impedance plane. The conductivity of zeolites was also calculated from Eq. (3). However, $l$ and $A$ is the thickness and surface area of the pellet, respectively.

\section{Results and discussion}

\subsection{Dealumination of Faujasite zeolite}

Table 1 summarizes the results of the physicochemical characterization of the parent and treated Faujasite zeolites. It was found from NAA analysis that the $\mathrm{Al} w \mathrm{w} \%$ is reduced by more than half, while Si wt\% remains unchanged. The increase of the Si/Al ratio from 48.7 to 103.7 indicates that CBV780 zeolite underwent serious dealumination during the treatment in $\mathrm{H}_{2} \mathrm{O}_{2} / \mathrm{H}_{2} \mathrm{O} / \mathrm{H}_{2} \mathrm{SO}_{4}$. However, as shown in the XRD patterns of Fig. 1, the Faujasite structure remained intact, and no other crystalline phases were detected. The diffraction peaks shifted to higher $2 \theta$ values and the unit cell 
Table 1

The physicochemical properties of the parent and dealuminated CBV780 zeolite (DA-CBV780) treated in $\mathrm{H}_{2} \mathrm{O}_{2} / \mathrm{H}_{2} \mathrm{O} / \mathrm{H}_{2} \mathrm{SO}_{4}$.

\begin{tabular}{lllclll}
\hline Sample & $\mathrm{Al}(\mathrm{wt} \%)$ & $\mathrm{Si}(\mathrm{wt} \%)$ & $\mathrm{Si} / \mathrm{Al} \mathrm{molar}$ & $a_{0}(\mathrm{~nm})$ & $S\left(\mathrm{~m}^{2} \mathrm{~g}^{-1}\right)$ & $V\left(\mathrm{~cm}^{3} \mathrm{~g}^{-1}\right)$ \\
\hline CBV780 & 0.87 & 44 & 48.7 & 24.24 & 823 & 0.5395 \\
DA-CBV780 & 0.38 & 41 & 103.7 & 24.21 & 735 & $7.6 \times 10^{-4}$ \\
\hline
\end{tabular}

parameter decreased (Table 1) consistently with the occurring of dealumination [34].

At variance with what previously observed by other authors [34], the specific surface area (SSA) of the Faujasite zeolite decreased from 823 to $735 \mathrm{~m}^{2} \mathrm{~g}^{-1}$ with the $\mathrm{H}_{2} \mathrm{O}_{2} / \mathrm{H}_{2} \mathrm{O} / \mathrm{H}_{2} \mathrm{SO}_{4}$ treatment (Table 1 ). This result was somewhat unexpected since extensive dealumination through acid leaching causes in general an increase of the surface area [34]. During the dealumination soluble $\mathrm{Al}-\mathrm{OH}_{2}{ }^{+}$species are produced and larger pores or even secondary pores in the mesopore region are formed. In fact, the analysis of the pore size distribution for the parent and dealuminated zeolites showed that the total micro pore volume decreased from 0.238 to $0.191 \mathrm{~cm}^{3} \mathrm{~g}^{-1}$, whereas the mesopore volume slightly increased. The decrease in the total SSA observed in the present case can thus be attributed to the accumulation of an amorphous phase (not detected by XRD) inside the zeolite micropores.

A lower proton conductivity was found for the dealuminated sample (Table 1). A decrease in the framework Al content causes a decrease in the number of exchangeable cations [22], protons in this case, although it increases the strength of the Brønsted sites [40]. Moreover, the lower micropore and total pore volumes found for the dealuminated Faujasite also affected negatively the proton mobility through the zeolite channels.

Although the Faujasite zeolite underwent extensive dealumination during the $\mathrm{H}_{2} \mathrm{O}_{2} / \mathrm{H}_{2} \mathrm{O} / \mathrm{H}_{2} \mathrm{SO}_{4}$ treatment, the structure did not collapse which is a requisite for operation in the strong acid and oxidative environment of DMFCs. The proton conductivity of the parent and dealuminated zeolites are three orders of magnitude lower than the reported proton conductivity of Nafion membranes (typically $0.1 \mathrm{~S} \mathrm{~cm}^{-1}$ for fully hydrated membrane at $25^{\circ} \mathrm{C}$ ).

\subsection{Nafion-Faujasite composite membranes}

TGA analysis was used to determine the real filler content in the composite membranes after the activation procedure, and to verify the impact of zeolite addition on the thermal stability of

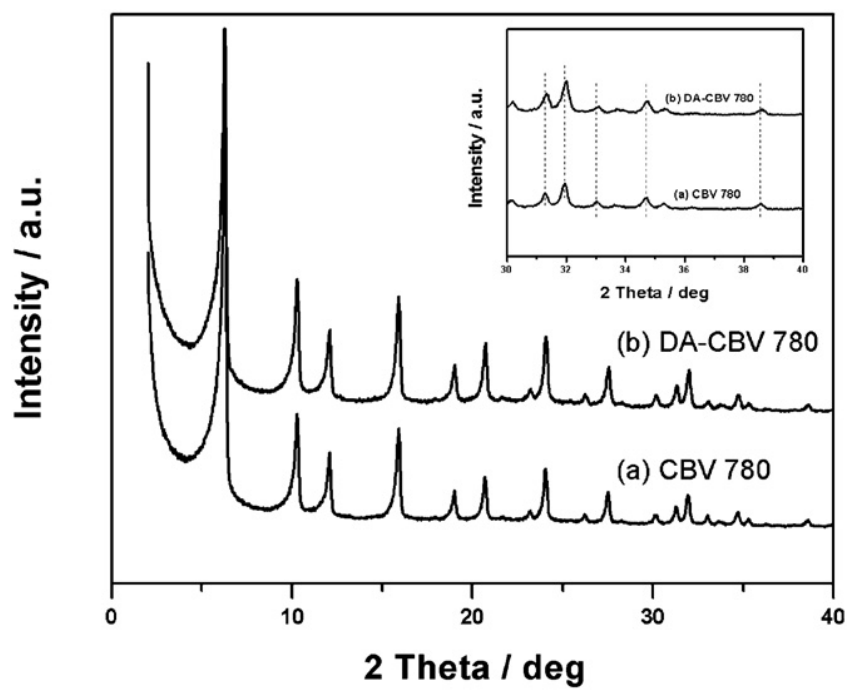

Fig. 1. XRD patterns of the parent (a) and the dealuminated (b) CBV780 zeolite. The insert is the enlarged view of the XRD at higher $2 \theta$ values.
Nafion. The real zeolite content was calculated after the subtraction of the water content and is shown in Table 2. The plot of the real zeolite content in the composite membranes vs. the nominal one (Fig. S1, Supplementary Material) shows a linear relation for both series of samples, and the slope of 0.49 for the fitted line means that the final filler content is about half of the zeolite initially added. The same variation on the ( $\mathrm{Si} / \mathrm{Al}) \mathrm{wt} \%$ was found by NAA on the zeolite powders (Table 1). Therefore, the major cause for the weight loss during the activation procedure is the leaching of $\mathrm{Al}$ from the zeolite framework during the treatment in hot $1.2 \mathrm{~mol} \mathrm{dm}^{-3} \mathrm{H}_{2} \mathrm{SO}_{4}$ solution, although it cannot be excluded that the Nafion's sulfonic group in the presence of water also contributed to the Faujasite dealumination. The linearity between the real and the nominal content, and the overlap between the two series of membranes indicates that the used fabrication procedure was well controlled.

Fig. 2a and $\mathrm{b}$ shows the TGA and DTG plots for the recast Nafion and for the N20_n series of composite membranes. Similar curves were obtained for the N5_n series of samples. The thermograms of the composite membranes exhibit a loss of weight during the initial stage at $25^{\circ} \mathrm{C}$ due to the evaporation of absorbed water under the $\mathrm{N}_{2}$ flow, the composite membrane with the highest zeolite loading showing the highest loss of water. The loss of water continues with increasing temperature. The thermal degradation of all membranes was found to undergo three similar stages as usually seen for Nafion in its acid form [41-46]: the first stage $\left(250-380^{\circ} \mathrm{C}\right)$ is due to the decomposition of the sulfonic acid groups, the second stage $\left(380-450^{\circ} \mathrm{C}\right)$ is related to the ether side-chain decomposition, and the third stage $\left(450-600^{\circ} \mathrm{C}\right)$ is due to the decomposition of PTFE backbone. The CBV780 crystals are stable in the scanned temperature range and the residues found above $600^{\circ} \mathrm{C}$ provided the real content of the zeolite in the composite membranes after the activation procedure.

Among the different factors that may contribute to define the thermal stability of Nafion-zeolite composite membranes the presence of the catalytically active $\mathrm{Al}^{3+}$ ions and the formation of $\mathrm{H}$-bonds between the polymer acid groups and $\mathrm{Si}-\mathrm{OH}$ functionalities on the fillers surface should certainly be taken into account. The decreased thermal stability observed for the composite membranes with respect to pristine Nafion cannot be attributed to the Lewis acid character of the $\mathrm{Al}^{3+}$ ion which is known to catalyze the degradation of Nafion ether bonds only in Al exchanged membranes $[44,47]$. But, the gradual increase of weight loss observed during the first stage seems to indicate that the Faujasite accelerates the thermal degradation of the sulfonic acid groups. However, all composite membranes show a $10-15^{\circ} \mathrm{C}$ shift of the DTG peaks to higher temperature with the incorporation of the zeolite (Fig. 2b). Such

Table 2

Nominal and real zeolite content (from TGA) of the composite membranes.

\begin{tabular}{lcc}
\hline Sample label & $\begin{array}{l}\text { Nominal zeolite } \\
\text { content (wt\%) }\end{array}$ & $\begin{array}{l}\text { Real zeolite } \\
\text { content (wt\%) }\end{array}$ \\
\hline N5_1 & 2 & 1.84 \\
N5_2 & 4 & 3.10 \\
N5_4 & 20 & 7.51 \\
N20_1 & 2 & 0.98 \\
N20_2 & 4 & 1.40 \\
N20_3 & 10 & 4.42 \\
N20_4 & 20 & 10.07 \\
N20_5 & 40 & 21.37 \\
\hline
\end{tabular}



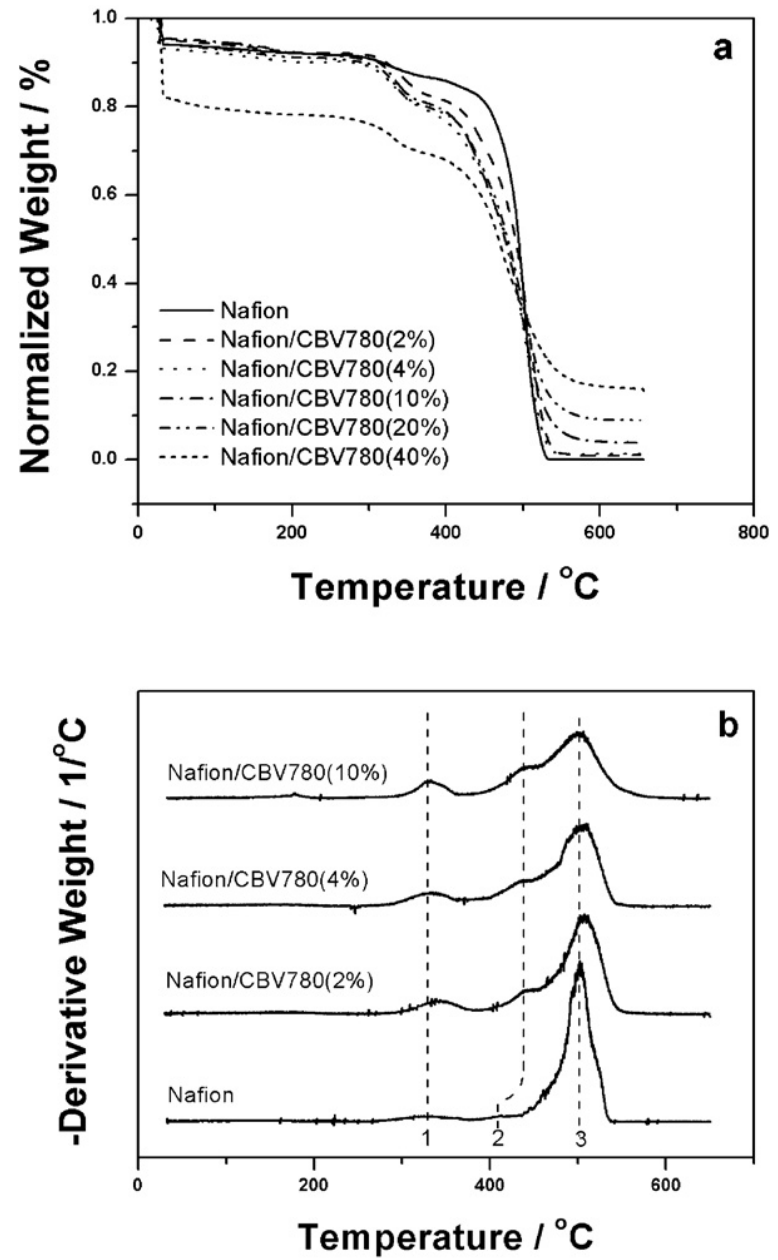

Fig. 2. TGA (a) and selected DTG (b) diagrams for the recast Nafion and composite membranes with various zeolite contents prepared from $20 \mathrm{wt} \%$ Nafion dispersion.

shift could be attributed to the stabilizing $\mathrm{H}$-bonding interactions between the polymer sulfonic acid groups and $\mathrm{Si}-\mathrm{OH}$ functionalities on the filler surface $[42,43,48]$. The parent Faujasite zeolite used in this work, CBV780, has a very high Si/Al molar ratio and therefore a high concentration of hydroxyl groups on the surface [35] which would favour the interaction between Nafion and the $\mathrm{SiOH}$ groups. Moreover, during the membrane activation the $\mathrm{Al}$ wt\% content decreased by half and consequently the number of silanol groups further increased. The decomposition of the sulfonic acid group involves the cleavage of the $\mathrm{C}-\mathrm{S}$ bond with the formation of $\mathrm{SO}_{2}$ [49], and because of the high zeolite loadings it is possible that in the present case the very strong interaction between $\mathrm{SO}_{3} \mathrm{H}-\mathrm{SiO}_{2}$ would weaken the $\mathrm{C}-\mathrm{S}$ bond. Indeed, it has been reported that the stabilizing $\mathrm{H}$-bonding interactions on Nafion- $\mathrm{SiO}_{2}$ composite membranes occurs only until a certain amount of filler [43].

Thus the overall thermal behavior may be explained taking into account the interplay of different effects: on one side the higher weight loss observed with respect to reference Nafion is due to the weakening of the $\mathrm{C}-\mathrm{S}$ bonds and on the other hand the DTG
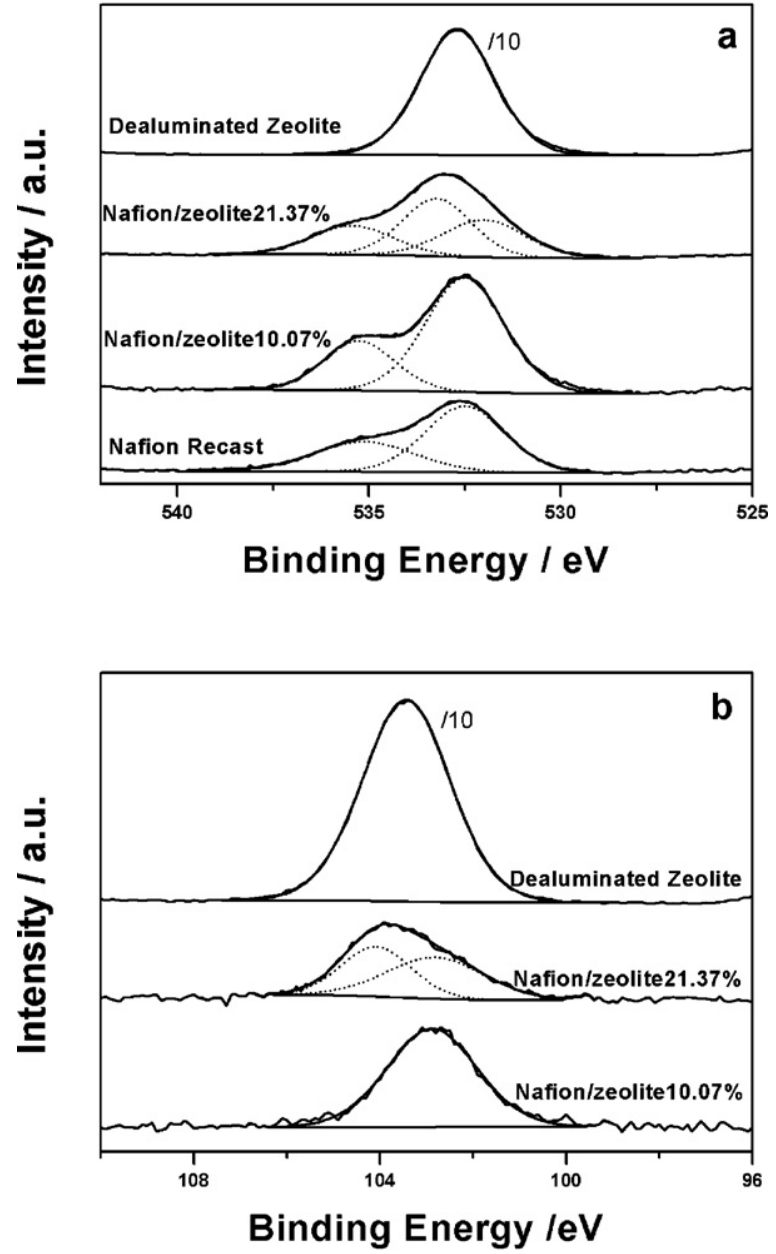

Fig. 3. $\mathrm{O}(1 \mathrm{~s})(\mathrm{a})$ and $\mathrm{Si}(2 \mathrm{p})(\mathrm{b})$ core level spectra of the dealuminated zeolite, recast Nafion and composite membranes N20_4 and N20_5.

peaks are shifted to higher temperature because of the existence of H-bonds between filler silanol and polymer sulfonic groups.

The recast Nafion membrane and composite membranes with the highest zeolite loading (N20_4 and N20_5) were characterized by XPS to complement the information obtained by TGA analysis. The survey and core level spectra of the bare Nafion are identical to those reported in the literature [50,51] and therefore not presented in this work. Si, but not Al, was found in the survey spectra of the composite membranes in addition to $\mathrm{C}, \mathrm{O}, \mathrm{F}$ and $\mathrm{S}$. Table 3 reports the $(\mathrm{S} / \mathrm{F}),(\mathrm{O} / \mathrm{F}),(\mathrm{Si} / \mathrm{F}),(\mathrm{S} / \mathrm{Si})$ and $(\mathrm{Si} / \mathrm{O})$ atomic ratios. The $(\mathrm{S} / \mathrm{F})$ ratio should be in principle independent of the zeolite content but it decreases to 0.0152 for the sample with the highest zeolite content, which indicates a lower concentration of sulfonic acid groups on the surface of the composite membrane. The $(\mathrm{O} / \mathrm{F})$ and $(\mathrm{Si} / \mathrm{F})$ ratios increase with the zeolite content as expected.

Table S1 summarizes the peak parameters for all resolved core level spectra as well as the assignment of the chemical species (see Supporting Information). No major variations were seen in the shape, width and number of peaks of the $C(1 s), F(1 s)$ and $S(2 p)$ spec-

Table 3

$(\mathrm{S} / \mathrm{F}),(\mathrm{O} / \mathrm{F}),(\mathrm{Si} / \mathrm{F}),(\mathrm{S} / \mathrm{Si})$ and $(\mathrm{Si} / \mathrm{O})$ atomic ratios of the dealuminated zeolite, recast Nafion and composite membranes with 10.07 wt\% and 21.37 wt\% zeolite from XPS.

\begin{tabular}{lllll}
\hline Sample & S/F & O/F & Si/F & S/Si \\
Nafion recast & 0.021 & 0.221 & - & - \\
N20_4 & 0.0193 & 0.243 & 0.054 & 0.357 \\
N20_5 & 0.0152 & 0.269 & 0.068 & 0.222 \\
Zeolite & - & - & - & 0.248 \\
\hline
\end{tabular}




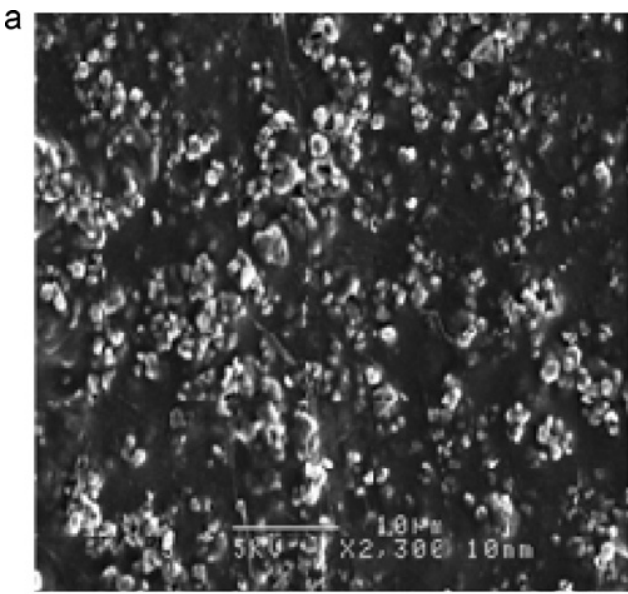

b
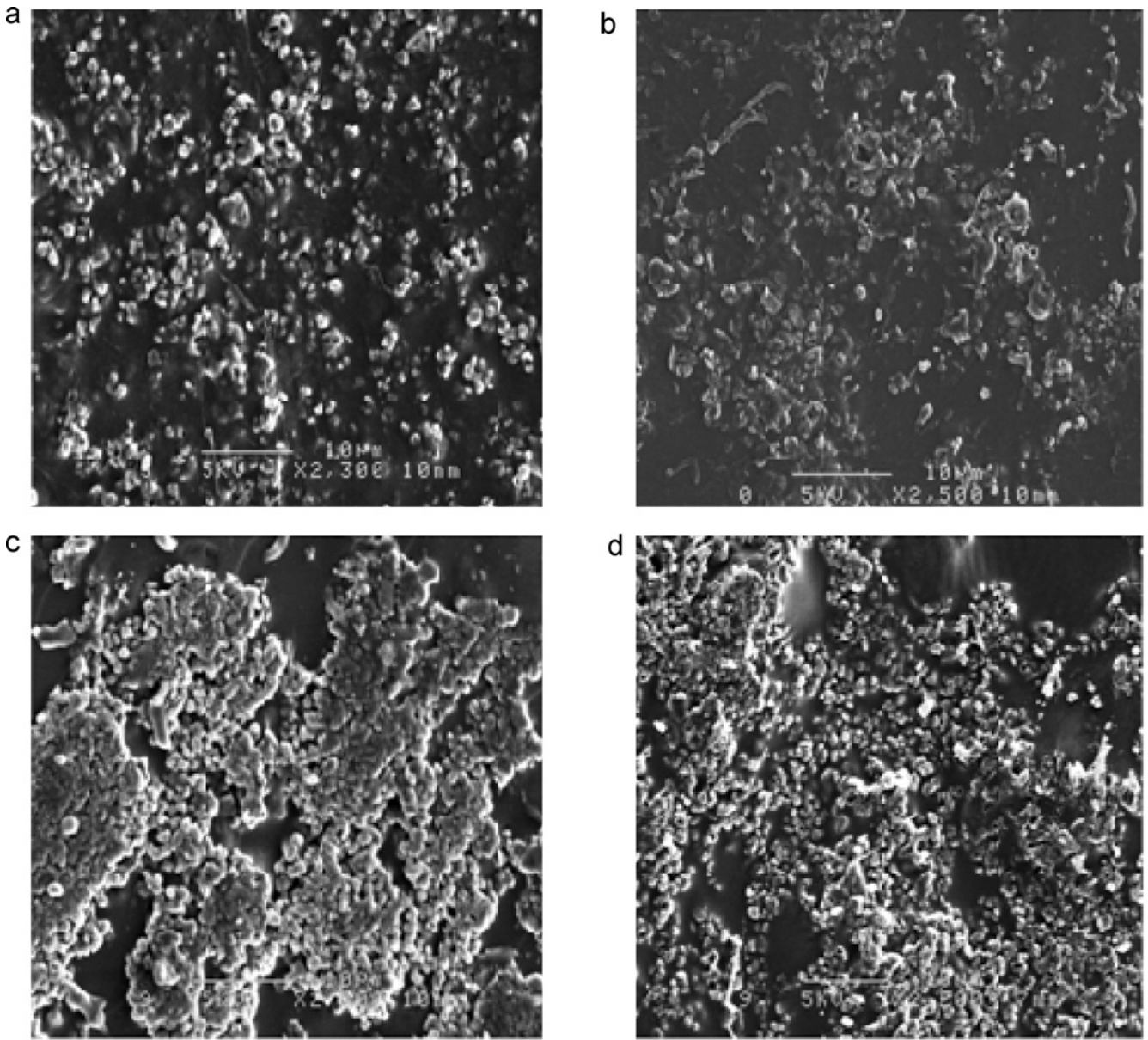

Fig. 4. SEM micrographs of the surface of the composite membranes N5_2 (a), N20_3 (b), with N5_4 (c), and N20_4 (d). All scale bars in the SEM micrographs are 10 $\mu$ m. The magnification for the above composite membranes is $2700 \times, 2500 \times, 2500 \times$, and $2200 \times$, respectively.

tra of Nafion by the addition of zeolite, but the shape of the $\mathrm{O}(1 \mathrm{~s})$ and $\mathrm{Si}(2 \mathrm{p})$ spectra of the composite membrane with the highest loading did change (see Fig. 3a and b). For comparison, the $\mathrm{O}(1 \mathrm{~s}$ ) and $\mathrm{Si}(2 \mathrm{p})$ spectra recorded for the dealuminated zeolite were also included in Fig. 3. The $\mathrm{O}(1 \mathrm{~s})$ spectrum of the composite membrane with the highest zeolite loading presents a third peak at $533.1 \mathrm{eV}$ attributed to the oxygen ions from the zeolite network. The second peak or shoulder present at higher binding energy in the $\mathrm{Si}(2 \mathrm{p})$ line clearly indicates a strong interaction between the zeolite surface and Nafion ionomer leading to a differentiation of the Si species. Such new peak/shoulder suggests a strong depletion of the electron density around certain $\mathrm{Si}$ species, which means that the Si-O bonding became more ionic or that the $\mathrm{Si}$ species are surrounded by a more electronegative element. The shift of $\mathrm{O}(1 \mathrm{~s})$ peak attributed to the zeolite network to higher binding energy values is consistent with the increase of the ionic character of the $\mathrm{Si}-\mathrm{O}$ bond, and supports the hypothesis of the strong interaction between silanol groups and sulfonic acid groups. Similar $\mathrm{Si}(2 \mathrm{p})$ core level spectrum and peak separation was observed by Blanco-Brieva on commercial fluorosulfonic acid Nafion ${ }^{\circledR}$ polymer on amorphous silica and on perfluorosulfonic acid-functionalized silica catalysts obtained from grafting 1,2,2-trifluoro-2-hydroxy-1-trifluoromethyl ethanesulfonic acid sultone onto the silica surface [52]. According to the authors this peak is indicative of an interaction between the Si and F atoms.

Fig. 4 shows some representative surface SEM micrographs of the composite membranes prepared from the two Nafion dispersions and with different zeolite contents. The morphology and distribution of the zeolite particles on the membrane surface seems to be independent on the concentration of the Nafion dispersion used to recast the membranes. On the other hand, and as expected, the aggregation of zeolite particles increases with the zeolite content. Fig. 5 shows the cross-section SEM micrographs of the N20_n series of membranes. In the micrographs relative to samples $\mathrm{N} 20 \_1$ and N20_2, the zeolite particles are hardly seen, due to the preferred sedimentation of the zeolite particles on the membrane surface during the preparation process. In all other samples the zeolite particles are easily observed on the membranes' cross-section together with pores and voids between particles and between the zeolites and the ionomer.

Fig. 6a reports the variation of the water uptake of the composite membranes as a function of the zeolite content for the two series of membranes prepared from the two Nafion dispersions. The water uptake of the membranes initially increases linearly with the zeolite content, and then it levels off for zeolite loadings higher than $8 \mathrm{wt} \%$. Zeolites are highly hydrophilic and have high water absorption capacity. In addition, SEM observations (Fig. 5) highlighted the porosity of the composite membranes, and the large number of defects and voids which can accommodate a significant amount of water.

To estimate the contribution of porosity (pores, defects and voids) to the water uptake, a third series of composite membranes was prepared from the $20 \mathrm{wt} \%$ Nafion dispersion and subjected to a hot press treatment at $140^{\circ} \mathrm{C}$ just before the activation procedure. As seen in Fig. 6b, the water uptake is lower for the hot pressed 
a

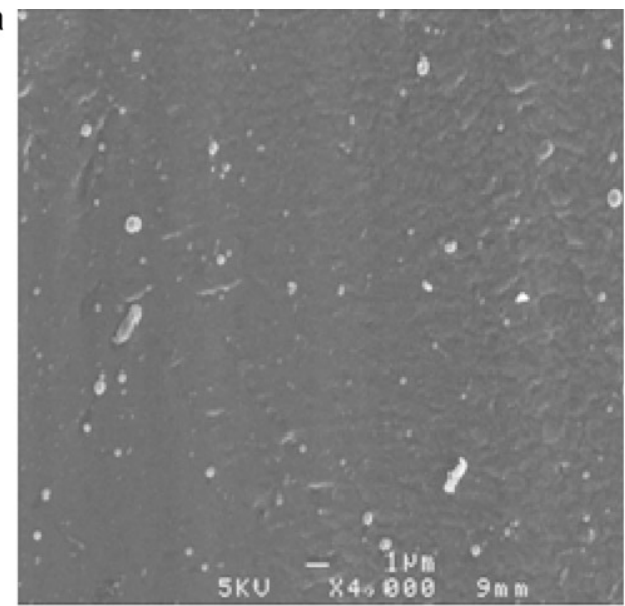

C
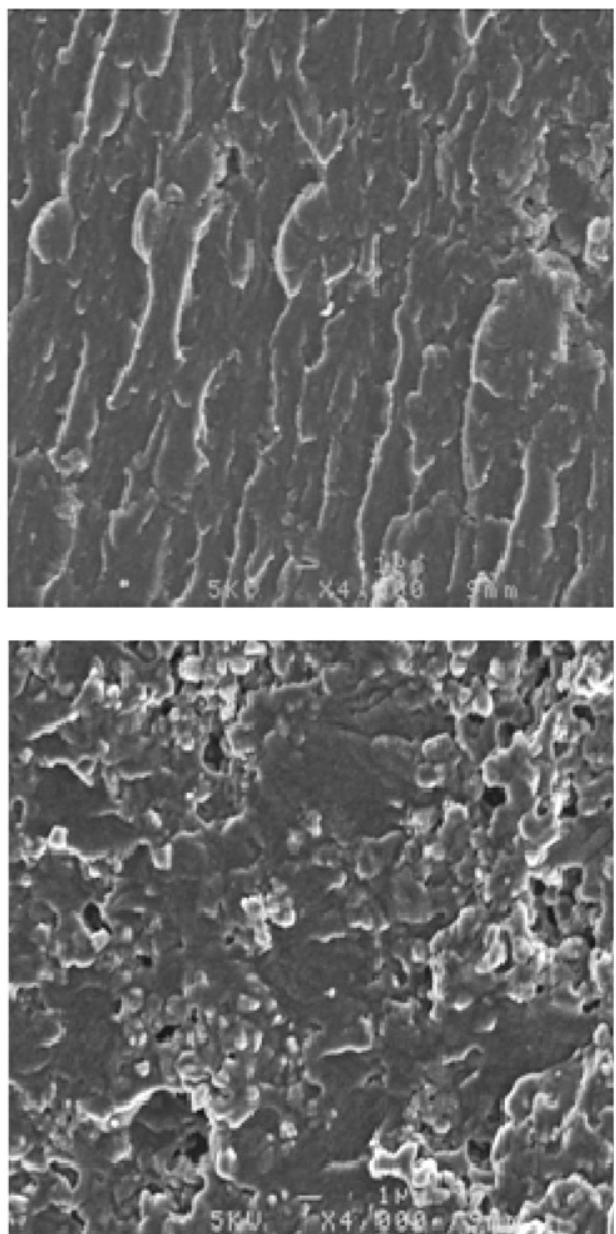

b

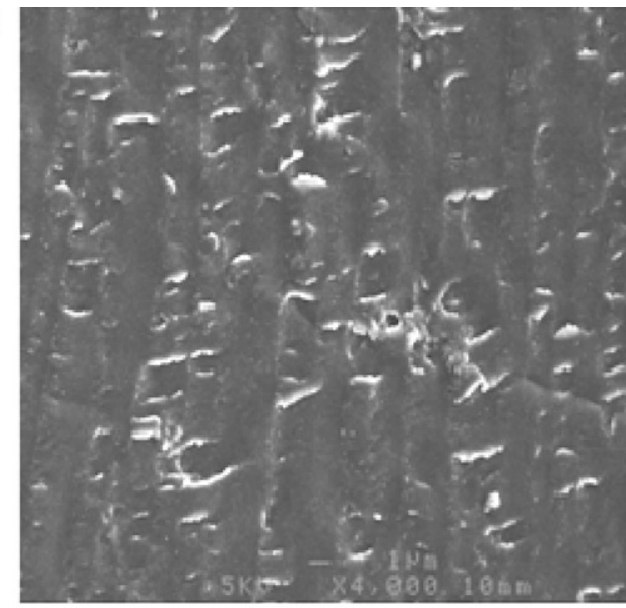

d
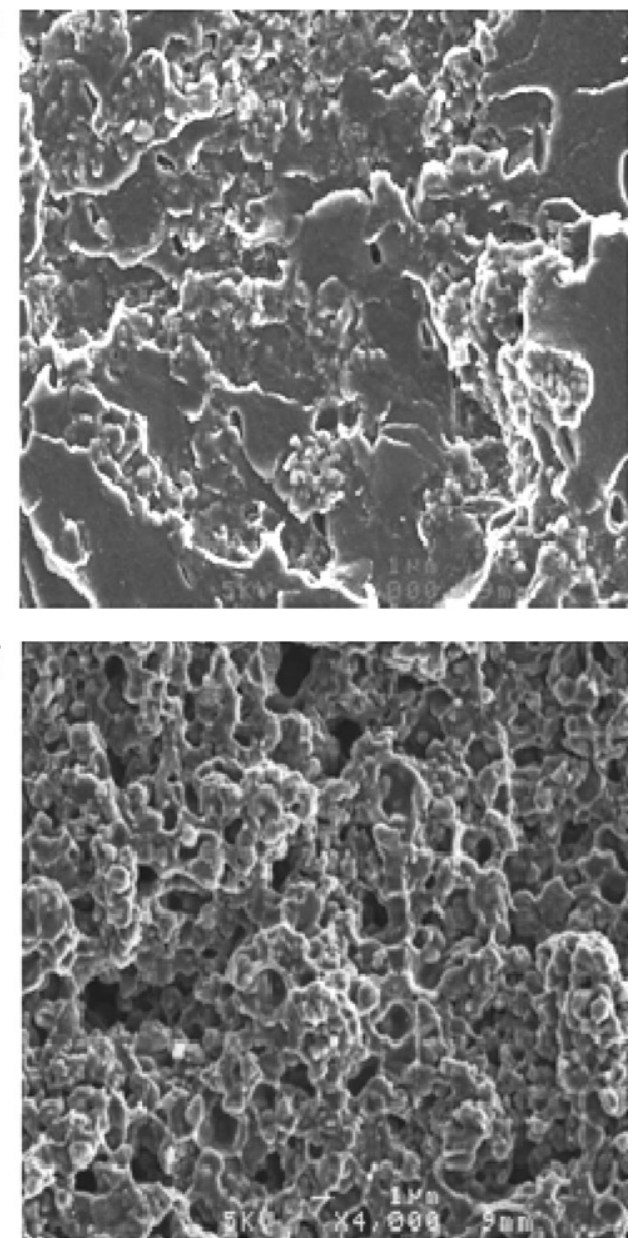

Fig. 5. Cross-section SEM micrographs of composite membranes prepared from 20 wt\% Nafion precursor; zeolite content: (a) reference Nafion; (b) N20_1; (c) N20_2; (d) N20_3; (e) N20_4; (f) N20_5. All scale bars and the magnifications in the SEM micrographs are $1 \mu \mathrm{m}$ and $4000 \times$, respectively.

composite membranes. The loss of porosity of the composite membranes was further quantified as follows:

Pore loss $(\%)=\frac{W U_{\mathrm{b}}-W U_{\mathrm{a}}}{W U_{\mathrm{b}}} \times 100$

where $W U_{\mathrm{b}}$ and $W U_{\mathrm{a}}$ denote the water uptake percentage of the composite membranes before and after hot pressing, respectively. The results (Fig. 6b) show that the porosity (including voids and defects) contribute to at least by $25 \%$ to the water uptake of the composite membranes (non-hot pressed). The cross-sectional SEM micrographs (not shown) also confirmed that the hot pressed composite membranes have lower open porosity.

The variation of the water uptake with the zeolite content for the hot pressed membranes is the same as for the others two series of membranes and it also levels off at $8 \mathrm{wt} \%$ zeolite. The levelling-off means there is an effect counteracting the strong water retention capacity of the zeolites which should have resulted in a continuous increase of the water uptake. The hydrophilic acid end groups of the ionomer are responsible for the water absorption of Nafion membranes. Therefore, a plausible cause is the decrease of the 

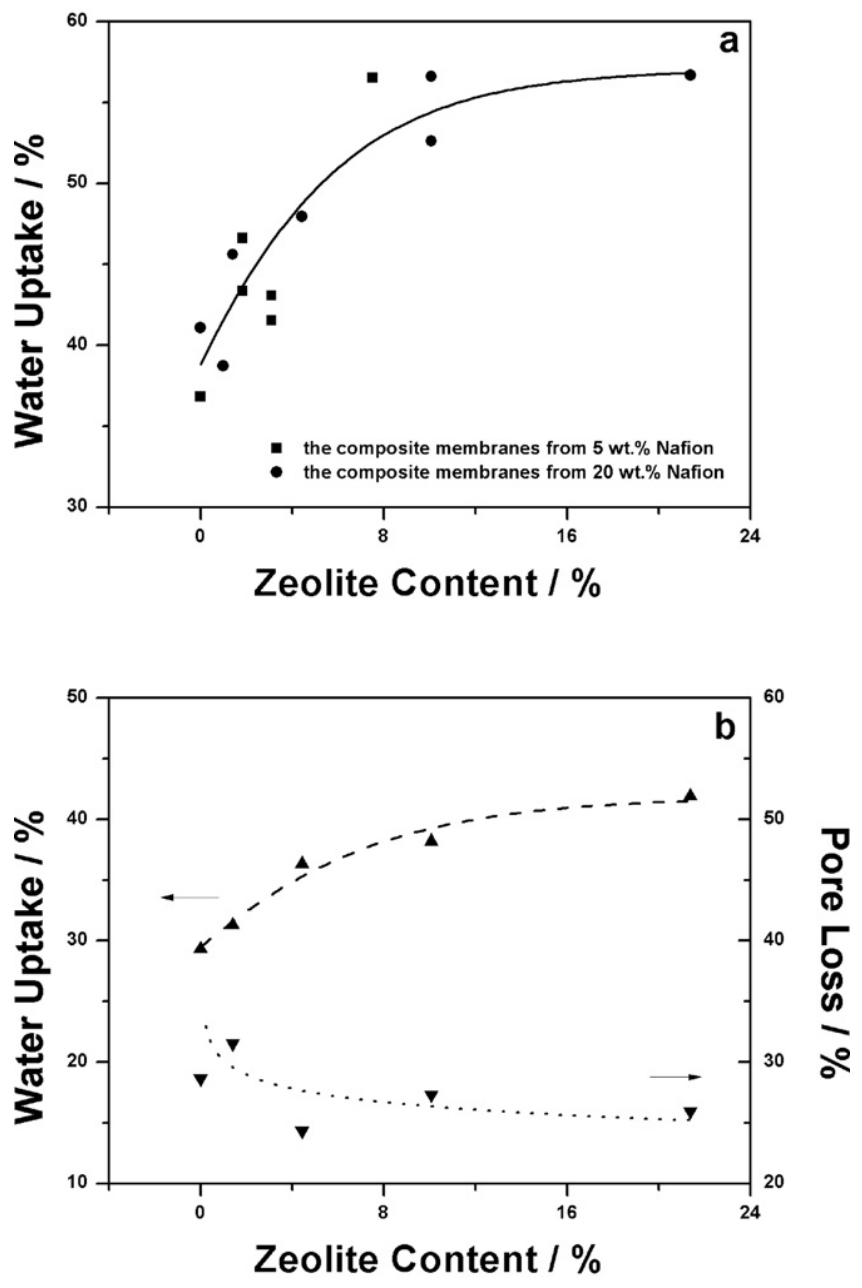

Fig. 6. (a) Variation of the water up-take as a function of the zeolite content for all composite membranes prepared from both 5 and $20 \mathrm{wt} \%$ Nafion dispersions; (b) variation of the water up-take and pore loss for the hot pressed composite membranes prepared from $20 \mathrm{wt} \%$ Nafion dispersions.

concentration of sulfonic acid groups since the fraction of Nafion in the composite membrane decreases with the increase of the zeolite content.

Such reduction also affected the ion exchange capacity (IEC) of the composite membranes. IEC was determined by acid base titration and, as expected, it decreases with the zeolite content. The theoretical and experimental IEC values agree well within the experimental error except for the highest loading of zeolite (21.37 wt\%) where it was found a noteworthy difference between the experimental and theoretical values of IEC: $0.66 \mathrm{mmol} \mathrm{g}^{-1} \mathrm{vs}$. $0.76 \mathrm{mmol} \mathrm{g}^{-1}$, respectively. This difference is in line with the smaller (S/F) surface ratio determined by XPS, thus confirming that for high loading of zeolite the fraction of sulfonic acid groups is lower than expected.

The water uptake and IEC were related through $\lambda$ defined as the ratio of the moles of water molecules $\left(n_{\mathrm{H}_{2} \mathrm{O}}\right)$ to the moles of $\mathrm{SO}_{3} \mathrm{H}$ groups $\left(n_{\mathrm{SO}_{3} \mathrm{H}}\right)$. Fig. 7 a presents $\lambda$ values as a function of IEC. In agreement with water uptake data, $\lambda$ increases with increasing zeolite content while the IEC decreases. Yet, the most significant feature is that a small decrease of the IEC is associated with a significant decrease of the concentration of sulfonic acid groups due to the large amount of water absorbed by the membranes. For example, with the addition of $7.51 \mathrm{wt} \%$ of zeolite to $5 \mathrm{wt} \%$ Nafion dispersion, IEC decreased from 0.98 to $0.82 \mathrm{mmol} \mathrm{g}^{-1}$ while $\lambda$ increased from 20.79 to 38.31 ; that is, the concentration of sulfonic acid groups
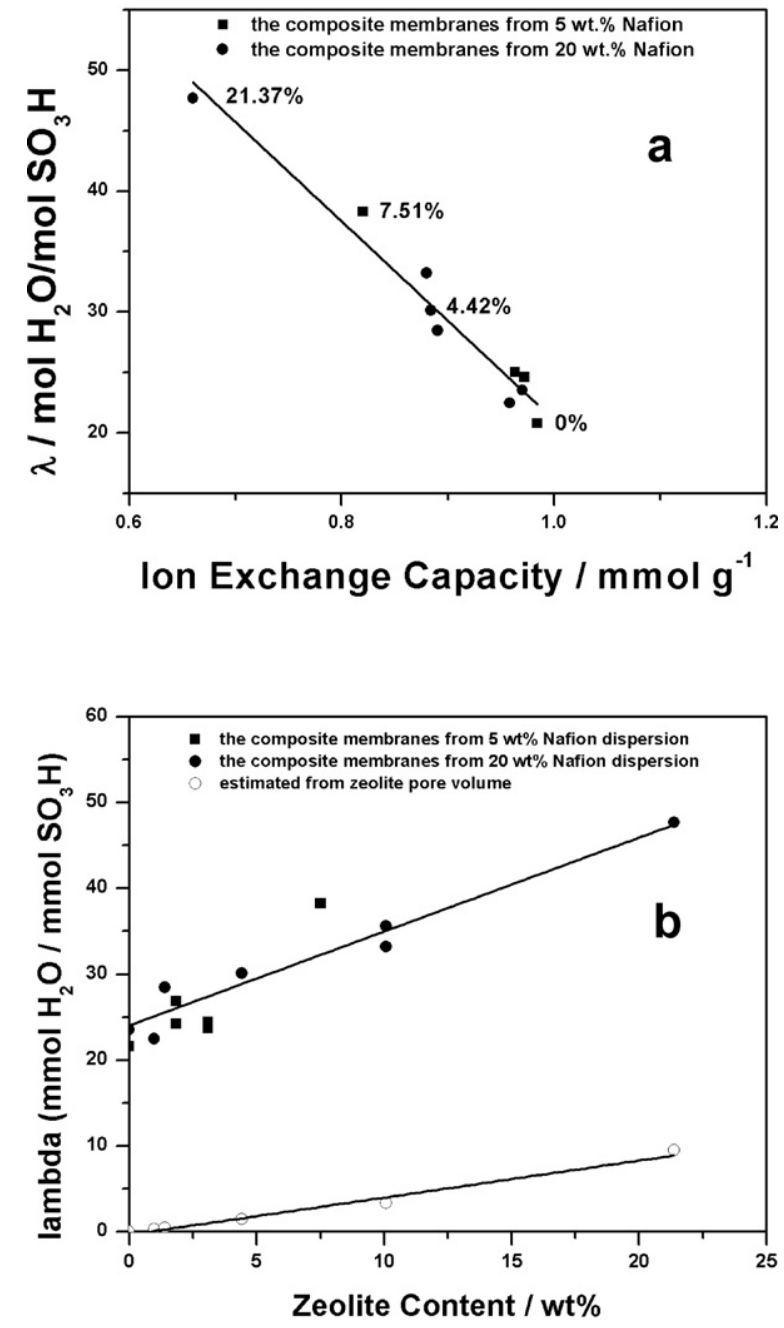

Fig. 7. (a) Variation of composite membranes' $\lambda$ as a function of the ion exchange capacity; (b) plot of experimental $\lambda$ and estimated $\lambda_{\text {zeolite }}$ as a function of the zeolite content. Linear fitting of the data is included as an aid for the eye.

decreased by $46 \%$ (Eq. (5)). These numbers show a major dilution of the proton concentration with the increase of the zeolite content.

$\left[\mathrm{SO}_{3} \mathrm{H}\right]=\frac{n_{\mathrm{SO}_{3} \mathrm{H}}}{V_{\mathrm{H}_{2} \mathrm{O}}}=\frac{\rho_{\mathrm{H}_{2} \mathrm{O}}}{\lambda \cdot M_{\mathrm{H}_{2} \mathrm{O}}}$

where $\rho_{\mathrm{H}_{2} \mathrm{O}}, V_{\mathrm{H}_{2} \mathrm{O}}$ and $M_{\mathrm{H}_{2} \mathrm{O}}$ are the density, volume and molar mass of water molecules, respectively.

The contribution of the zeolite bulk hydration to the membranes' lambda was estimated from the zeolite pore volume $\left(0.5274 \mathrm{~cm}^{3} \mathrm{~g}^{-1}\right)$ using the following equation:

$\lambda_{\text {zeolite }}=\frac{1000 \cdot x \cdot 0.5274}{18 \cdot \operatorname{IEC}}$

where $x$ is the zeolite content $(\mathrm{g})$ per gram of membrane, 18 is the molecular weight of water, 0.5274 is the water uptake of zeolite per gram of membrane, 1000 is a unit conversion factor, IEC being expressed in mequiv. $\mathrm{g}^{-1}$. Fig. 7b shows the comparison between experimental $\lambda$ and theoretical $\lambda_{\text {zeolite }}$ values of N_5 and N_20 membrane as a function of zeolite loading. Both $\lambda$ values were found to increase linearly with zeolite content, indicating that the membranes' hydration level is proportional to the filler content. However, the experimental $\lambda$ values showed a larger increase with respect to theoretical $\lambda_{\text {zeolite }}$ values, indicating that the contribution to the water uptake of membranes is not only due to the filler hydration. Indeed, porosity and voids formed between the zeolite 


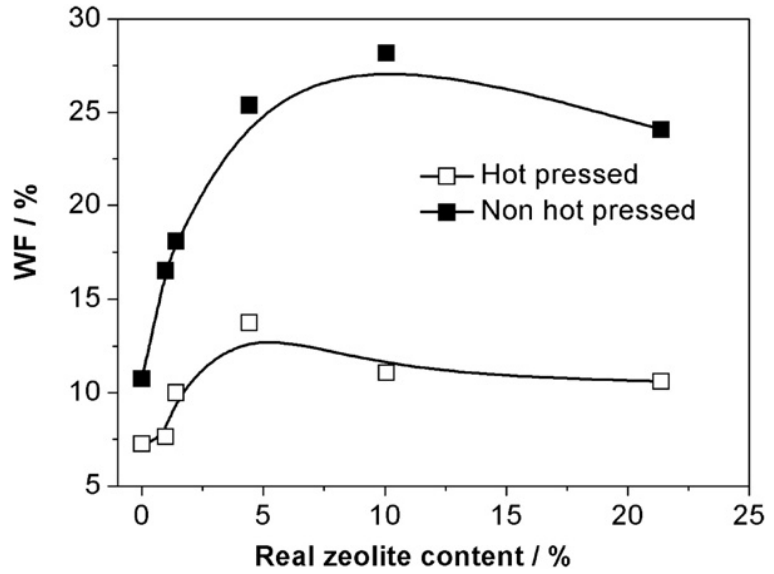

Fig. 8. Percentage of freezable water $\left(W_{\mathrm{F}} \%\right)$ in the Nafion based composite membranes prepared from $20 \mathrm{wt} \%$ Nafion dispersion as a function of zeolite content; non hot pressed membranes (solid square) and hot pressed membranes (empty square).

particles and between the zeolite and ionomer have to be accounted for the $\lambda$ trend.

Proton conductivity is given by the number of carriers multiplied by their mobility. Water is a vehicle for protons during the proton conduction process and an increase of the water content inside the membrane increases the proton mobility according to the vehicle mechanism [53]. On the other hand, the increase of water uptake dilutes the protons and decreases the density of carriers. Therefore, the change in the water content and water mobility must have an impact on the proton conductivity of the composite membranes.

To gain a deeper understanding about water mobility in the composites, the state of water in the membranes was investigated by DSC which allows discriminating between freezable and non-freezable water. Non-freezable water is strongly bound to the polymer matrix and yields no characteristic thermal transition in DSC thermograms. Freezable water $\left(W_{\mathrm{F}}\right)$ is more mobile and exhibits thermal transitions similar to bulk water. Since the presence of bulk-like water increases the mobility of protons, $W_{\mathrm{F}}$ is important for proton conductivity $[54,55]$. The heating run of the DSC thermograms of the unfilled Nafion and composite membranes (see Fig. S2, Supporting Information) show for all samples a broad endothermic peak corresponding to the melting of freezable water in the $0-0{ }^{\circ} \mathrm{C}$ temperature range. The percentage amount of freezable water $\left(W_{\mathrm{F}} \%\right)$ in the membranes was calculated according to Eq. (7):

$W_{\mathrm{F}} \%=\frac{A}{\Delta H_{\mathrm{W}}} \frac{1}{m_{\mathrm{d}}} \times 100$

where $A$ is the area of the endotherm peak, $\Delta H_{\mathrm{W}}$ is the enthalpy of melting for bulk water $\left(333 \mathrm{Jg}^{-1}\right)$ and $m_{\mathrm{d}}$ is the mass of the dried sample [56].

Fig. 8 shows the $W_{\mathrm{F}} \%$ values as a function of the real zeolite content for the N20_n and N20_n_HP series of membranes. For both series, the $W_{\mathrm{F}} \%$ values increased with the filler loading up to sample N20_4 (4.42 wt.\% zeolite content) and at higher zeolite contents $W_{\mathrm{F}} \%$ reached a saturation threshold. In the whole range of zeolite concentration investigated, the $W_{\mathrm{F}} \%$ values of the composites were higher than those of the unfilled Nafion membranes, the differences being less pronounced in the case of the hot pressed membranes, owing to their lowered porosity. Previous authors have illustrated that proton conductivity is highest for membranes with larger freezable water contents [54], thus higher $W_{\mathrm{F}} \%$ is expected to lead to higher proton conductivity values.

Both through-plane and in-plane proton conductivities were measured and show the same general trend. Data are shown in

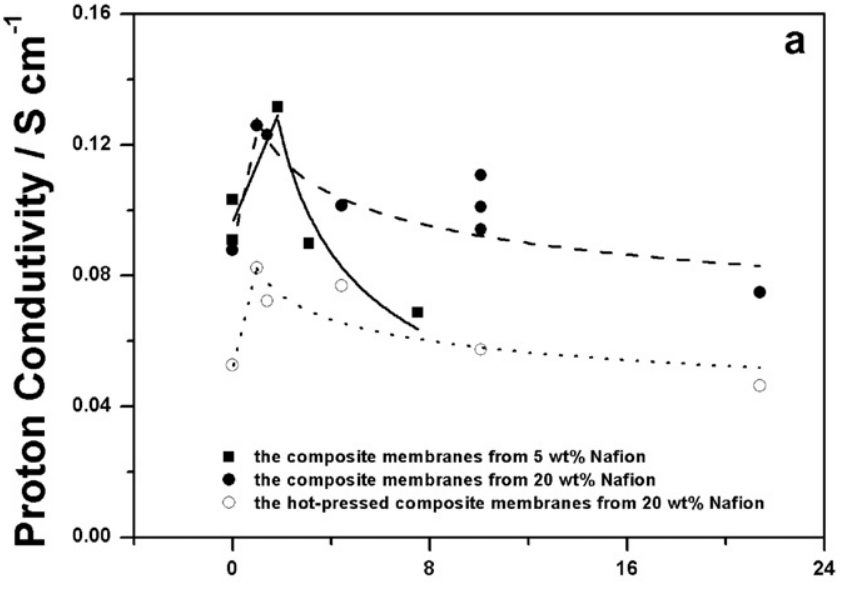

Zeolite Content $/ \%$

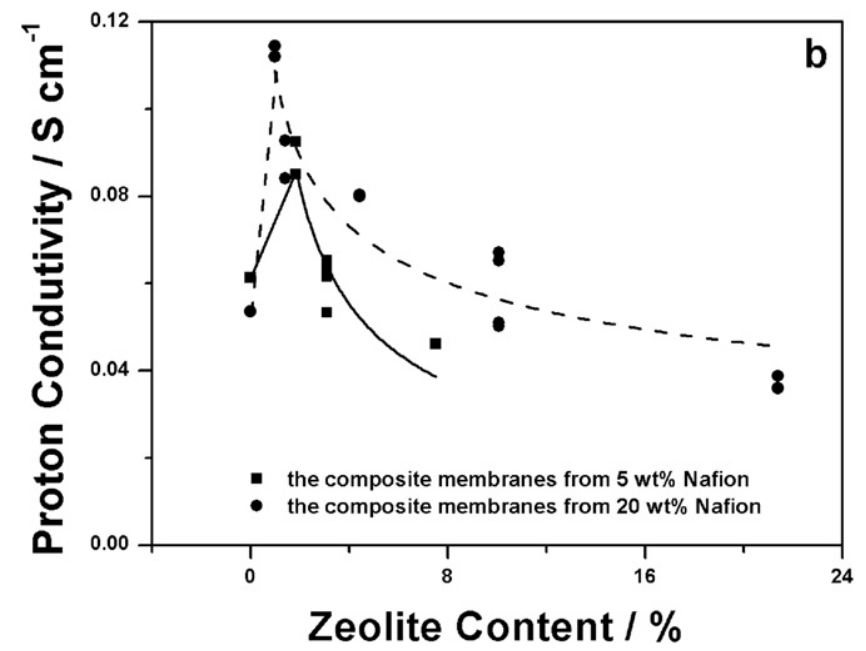

Fig. 9. (a) Variation of the through-plane proton conductivity with the zeolite content for membranes prepared from $5 \mathrm{wt} \%$ Nafion dispersion (solid square), from 20 wt\% Nafion dispersion (solid circle) and from 20 wt\% Nafion dispersion after hot pressing (empty circle); (b) variation of the in-plane proton conductivity as function of the zeolite content. Non-linear fitting curves are included as an aid for the eye.

Fig. 9. Fig. 9a shows the through-plane proton conductivity of all the composite membranes prepared. For all samples the throughplane proton conductivity increases initially with filler content, then gradually decreases. The maximum through-plane conductivity is $0.13 \mathrm{~S} \mathrm{~cm}^{-1}$ and ca. $45 \%$ higher than the values recorded for the bare Nafion membranes prepared by solution casting. At low zeolite content, the increase of the membranes' water up-take and of the mobility of water is predominant and an enhancement of proton conductivity of the composite membranes is observed. At high zeolite content, the decrease of conductivity can be related to a dilution effect due to the addition of a less conducting phase [57] in addition to the decrease of sulfonic avid groups available for proton transfer, as indicated by the low IEC. The same trend is seen for the hot pressed membranes but it is translated vertically towards lower conductivity. The decrease in proton conductivity (ca. 40\%) results from the decrease of water uptake (ca. 25\%) and proton mobility (from DSC analysis), due to the reduction of porosity after the hot pressing procedure.

The in-plane conductivity (Fig. 9b) exhibits the same trend confirming the above explanation. The maximum in-plane conductivity is $0.11 \mathrm{~S} \mathrm{~cm}^{-1}$ and is ca. $110 \%$ higher than the values recorded for the bare Nafion membrane prepared by solution cast- 
ing. Noteworthy, the same or almost the same values of proton conductivity were determined from both sides of the membranes. For all non-hot pressed membranes, the in-plane proton conductivity is lower than the through-plane proton conductivity. Moreover, the ratio of through-plane to in-plane conductivity for the composite membranes increases with increasing zeolite content. Although anisotropic proton conductivity has been reported in the literature and was shown to be dependent on the membrane casting method, membrane pretreatment procedure such as hot pressing, and membrane morphology [58-65], it is obvious that the porosity/voids of these Nafion-Faujasite composite membranes contribute for this difference. In fact, by hot pressing the membranes the two conductivity values become very similar.

Our Nafion-Faujasite (0.98-2 wt\%) composite membranes have higher proton conductivity than the pure recast Nafion membrane, owing to the higher mobility of water and still high concentration of protons. Some works have reported a decrease of ionic conductivity of composite membranes after the addition of zeolites [25,31], but overall the impact of the zeolite addition varies in the literature. The use of different types of zeolites (structure, Si/Al ratio, surface area), particle sizes, membrane preparation procedure might explain the differences reported in the literature. The very high surface area of the zeolite used in this work seems to be responsible for the increase of the water up-take and enhancement of the proton conductivity of the composite membranes for real Faujasite contents inferior to $4 \mathrm{wt} \%$.

\subsection{The effect of the membrane hot pressing on DMFC performance}

The impact of the membranes' morphology and the hot press procedure on the DMFC performance was investigated. Two composite membranes were tested: N20_2 and N20_2_HP. Their average membrane thickness was $165 \mu \mathrm{m}$ and $130 \mu \mathrm{m}$, respectively. We are targeting DMFC for portable applications (ideally air breathing DMFCs), and since the performance of the DMFCs fed with air at the cathode at $25^{\circ} \mathrm{C}$ is very low, measurements were carried out at $40^{\circ} \mathrm{C}$, i.e. at the lowest temperature at which the DMFC fuel cells performance is sufficiently good (in terms of OCV and current density) to perform a comparative study on two different membranes.

Fig. 10 reports the polarization curves recorded at $40^{\circ} \mathrm{C}$ with $1 \mathrm{M}$ methanol solution fed at the anode and air at the cathode. The higher open circuit voltage (OCV) recorded for the cell equipped with the hot pressed membrane $(0.58 \mathrm{~V}$ vs. $0.52 \mathrm{~V}$ for the non pressed membrane) despite its lower thickness indicates a decreased methanol crossover [66] and underlines the importance of minimizing porosity and voids during the fabrication of composite membranes. The DMFC with the hot pressed membrane exhibits better performance in terms of maximum power density $\left(P_{\max }, 17.8 \mathrm{~mW} \mathrm{~cm}^{-2} \mathrm{vs} .12 .4 \mathrm{~mW} \mathrm{~cm}^{-2}\right)$, and the polarization curve extends into the higher current range. The series resistance measured by EIS (Table 4) is higher for the DMFC based on the (thicker) non-hot pressed membrane and accounts for the difference in performance since the IR-corrected polarization curves (not shown) almost overlap in the ohmic loss region.

The non-hot pressed membrane presented the highest throughplane conductivity $\left(0.13 \mathrm{~S} \mathrm{~cm}^{-1}\right.$, Fig. $\left.9 \mathrm{a}\right)$, and based on this number the membrane resistance would account only for $52 \%$ of the DMFC series resistance. The hot pressed membrane has lower proton conductivity $\left(0.07 \mathrm{~S} \mathrm{~cm}^{-1}\right.$, Fig. $\left.9 \mathrm{~b}\right)$ and the membrane resistance would account for $81 \%$ of the DMFC resistance. This analysis suggests that after assembling the non hot-pressed membrane with the porous anode and cathode at $140^{\circ} \mathrm{C}$, the effective through-plane conductivity of the membrane is lower than $0.13 \mathrm{~S} \mathrm{~cm}^{-1}$. In addition, from the lower OCV values, it can be concluded that the assembling procedure with the porous electrodes is not effective as first (or ex situ)
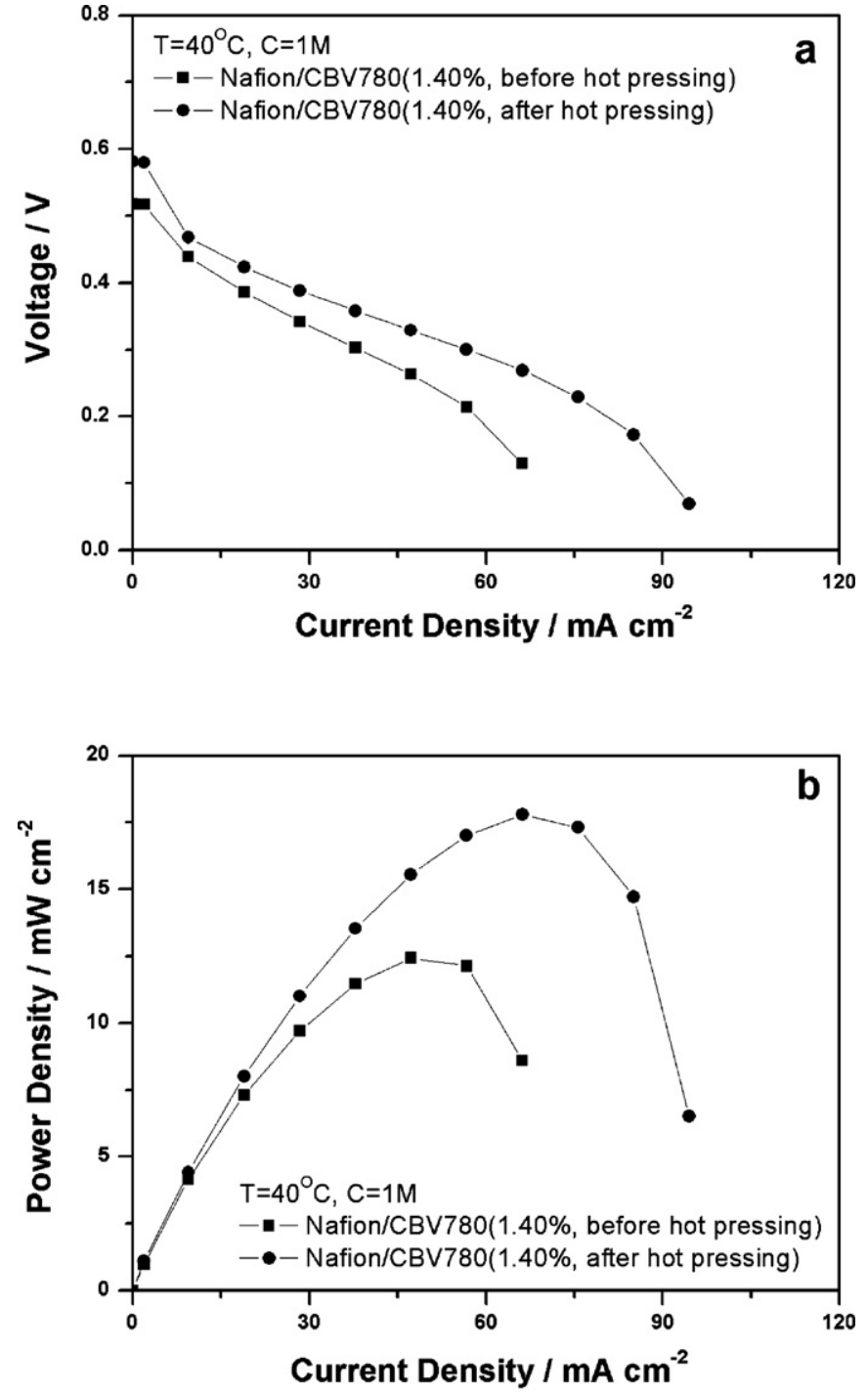

Fig. 10. Polarization curves of the DMFC single cell based on the non- and hotpressed composite membranes with $1.40 \mathrm{wt} \%$ zeolite prepared from $20 \mathrm{wt} \%$ Nafion dispersion. The measurements were done at $40{ }^{\circ} \mathrm{C}$ with $1 \mathrm{~mol} \mathrm{dm}^{-3}$ methanol and air (atmospheric pressure).

hot pressing the membranes between the smooth plates of a hot pressing.

Polarization curves were recorded for different methanol concentrations between 1 and $10 \mathrm{moldm}^{-3}$, and the impact on the OCV and $P_{\max }$ is shown in Fig. 11. The OCV decreases with methanol concentration, as expected from the very low zeolite

Table 4

Series resistance of DMFCs operating at $40^{\circ} \mathrm{C}$ and equipped with Nafion-zeolite $(1.40 \mathrm{wt} \%)$ composite membranes as a function of the methanol concentration fed at the anode.

\begin{tabular}{lcl}
\hline Membrane & {$[\mathrm{MeOH}]\left(\mathrm{mol} \mathrm{dm}^{-3}\right)$} & $R_{\mathrm{s}}{ }^{\mathrm{a}}\left(\mathrm{m} \Omega \mathrm{cm}^{2}\right)$ \\
\hline N20_2 & 1 & 257 \\
& 2 & 259 \\
& 5 & 279 \\
& 10 & 323 \\
N20_2_HP & 1 & 222 \\
& 2 & 229 \\
& 5 & 241 \\
& 10 & 255 \\
\hline
\end{tabular}

a Serial resistance $R_{\mathrm{S}}$ was determined from EIS data of DMFCs. 

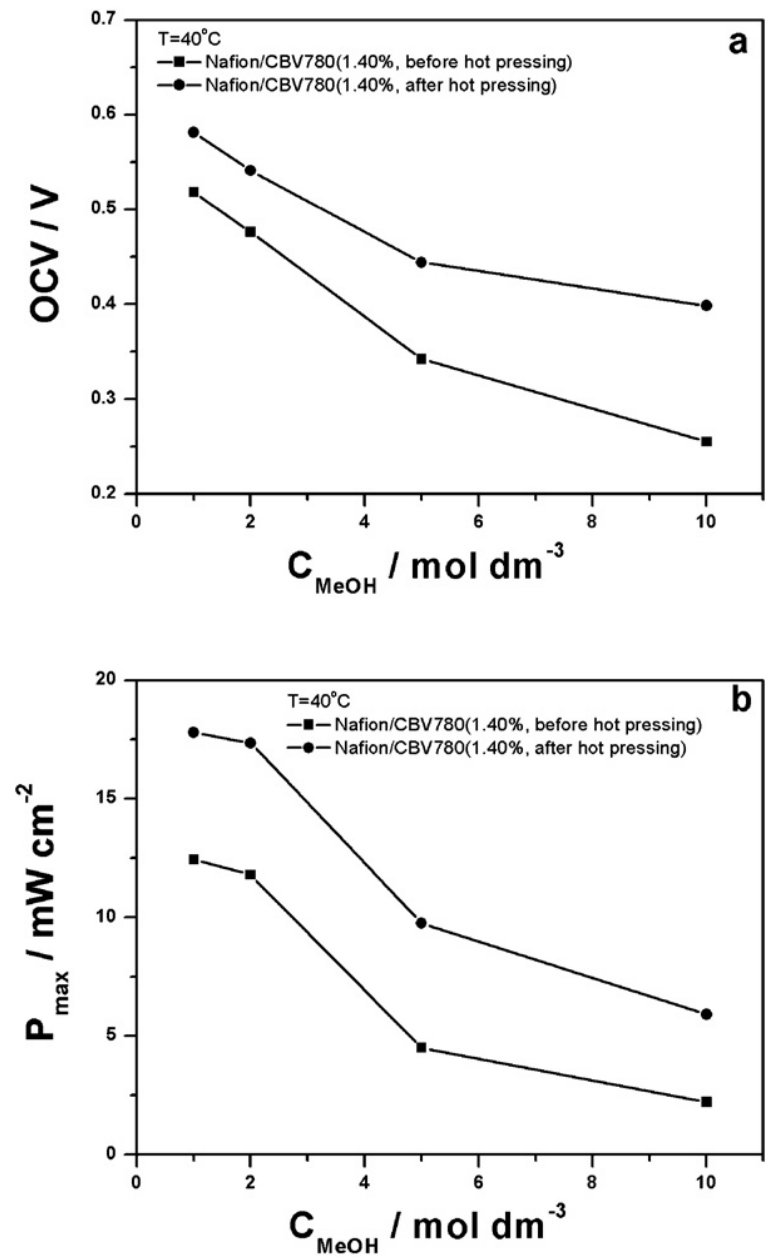

Fig. 11. Variation of the open circuit voltage (OCV) and maximum power density $\left(P_{\max }\right)$ with methanol concentration of DMFCs equipped with the non- and hotpressed composite membranes with $1.40 \mathrm{wt} \%$ zeolite prepared from $20 \mathrm{wt} \%$ Nafion dispersion. The measurements were done at $40{ }^{\circ} \mathrm{C}$ with $1-10 \mathrm{~mol} \mathrm{dm}^{-3}$ methanol and air (atmospheric pressure).

content, but it is always higher for the hot pressed membrane. In addition, the gap between the OCVs values increases with the methanol concentration. This result further confirms that ex situ hot pressing of composite membranes is important to decrease the porosity and voids within these membranes, being particularly effective at higher methanol concentration. The $P_{\max }$ recorded for the DMFC equipped with the hot pressed membrane was higher by ca. $5.0 \mathrm{~mW} \mathrm{~cm}^{-2}$ for $1-5 \mathrm{~mol} \mathrm{dm}^{-3}$ methanol solutions and $3.7 \mathrm{~mW} \mathrm{~cm}^{-2}$ for $10 \mathrm{~mol} \mathrm{dm}^{-3}$ methanol solution. The relatively low temperature $\left(40^{\circ} \mathrm{C}\right)$, low Pt loading in the electrodes and air feed at the cathode explain the lower OCV and $P_{\max }$ values with respect to those reported in the literature for Nafion-zeolite composite membranes which membranes were in general tested at higher temperature $\left(>70^{\circ} \mathrm{C}\right)$ and with pressurized oxygen at the cathode [67-69].

There is a systematic increase of the DMFC series resistance with the methanol concentration (Table 4) which reflects a decrease of the membranes' proton conductivity. The same tendency was observed on MEAs fabricated with commercial Nafion (115 and 117 ) and recast Nafion membranes, equipped with the same commercial or in-house prepared electrodes (data not shown). Moreover, the increase of the series resistance is more significant for thicker membranes. It has been recently reported that the proton conductivity of Nafion and CM2 hydrocarbon membranes measured ex situ also decreased with the increase of the methanol concentration, and the lower conductivity was attributed to the lower ionization of methanol with respect to water molecules [70]. Further studies are in progress to investigate this effect since it might be an additional cause for the low performance of the DMFCs fed with high methanol concentration.

\section{Conclusions}

Nafion-Faujasite composite membranes were prepared by solution casting technique from commercial Nafion dispersions and CBV780 Faujasite powders. NAA, XRD and $\mathrm{N}_{2}$ adsorption measurements indicate that the Faujasite underwent severe dealumination during the membrane activation but their structure did not collapse. The real zeolite content on the activated composite membranes was found to be half of the nominal one. TGA and XPS suggest the existence of a strong interaction between Nafion's sulfonic acid groups and the $\mathrm{SiOH}$ groups of the zeolite. The optimum proton conductivity of the composite membranes was found to be between 0.98 and $2 \mathrm{wt} \%$ of real zeolite content and related to the increase of the mobility of water on the fully hydrated membranes. Yet, the impact of the zeolite addition, and in particular the increase of proton conductivity, can only be assessed after testing the membranes in DMFC. Preliminary DMFC tests on composite membranes with $1.40 \mathrm{wt} \%$ zeolite have shown that hot pressing the membranes prior to assembling with electrodes reduces methanol crossover by decreasing porosity, lowers the membrane thickness and the DMFC serial resistance, and thus improves the DMFC performance. The increase of DMFC series resistance suggests the decrease of the Nafion proton conductivity with increasing methanol concentration. Zeolites are promising membrane materials for DMFCs but the type of zeolite has to be carefully chosen and the composite membranes extensively characterized due to the large number of variables that can affect the characteristics of the composite membranes. A comparative study with Faujasites with different Si/Al ratio and SSA, and other zeolites with similar SSA is in progress to verify the relation between surface area, water uptake characteristics and electrical properties.

\section{Acknowledgements}

This work was realized with the financial support of the National Science and Engineering Research Council (NSERC) of Canada and the Canadian Foundation for Innovation, and of the Italian Ministry for Foreign Affairs and the Ministère du Développement Economique, l'Innovation et l'Exportation du Québec (Italy-Québec Joint Lab for Advanced Nanostructured Materials for Energy, Catalysis and Biomedical Applications).

\section{Appendix A. Supplementary data}

Supplementary data associated with this article can be found, in the online version, at doi:10.1016/j.jpowsour.2011.07.009.

\section{References}

[1] B.D. McNicol, D.A.J. Rand, K.R. Williams, J. Power Sources 83 (1999) 15

[2] S. Wasmus, A. Kuver, J. Electroanal. Chem. 461 (1999) 14

[3] S. Tominaka, S. Ohta, H. Obata, T. Momma, T. Osaka, J. Am. Chem. Soc. 130 (2008) 10456.

[4] H.S. Liu, C.J. Song, L. Zhang, J.J. Zhang, H.J. Wang, D.P. Wilkinson, J. Power Sources 155 (2006) 95.

[5] V. Neburchilov, J. Martin, H. Wang, J. Zhang, J. Power Sources 169 (2007) 221.

[6] V. Paganin, E. Sitta, T. Iwasita, W. Vielstich, J. Appl. Electrochem. 35 (2005) 1239.

[7] C.Y. Du, T.S. Zhao, W.W. Yang, Electrochim. Acta 52 (2007) 5266.

[8] S. Siracusano, A. Stassi, V. Baglio, A.S. Arico, F. Capitanio, A.C. Tavares, Electrochim. Acta 54 (2009) 4844

[9] B. Baradie, J.P. Dodelet, D. Guay, J. Electroanal. Chem. 489 (2000) 101.

[10] A.S. Arico, V. Baglio, A. Di Blasi, P. Creti, P.L. Antonucci, V. Antonucci, Solid State Ionics 161 (2003) 251. 
[11] W.L. Xu, T.H. Lu, C.P. Liu, W. Xing, Electrochim. Acta 50 (2005) 3280.

[12] K.A. Mauritz, Mater. Sci. Eng. C 6 (1998) 121

[13] H. Uchida, Y. Ueno, H. Hagihara, M. Watanabe, J. Electrochem. Soc. 150 (2003) A57.

[14] A. Sacca, A. Carbone, E. Passalacqua, A. D’Epifanio, S. Licoccia, E. Traversa, E. Sala, F. Traini, R. Ornelas, J. Power Sources 152 (2005) 16.

[15] F. Damay, L.C. Klein, Solid State Ionics 162-163 (2003) 261.

[16] H.C. Kuan, C.S. Wu, C.Y. Chen, Z.Z. Yu, A. Dasari, Y.W. Mai, Electrochem. Solid State Lett. 9 (2006) A76.

[17] A.K. Sahu, S. Pitchumani, P. Sridhar, A.K. Shukla, Fuel Cells 9 (2009) 139.

[18] A. D'Epifanio, M.A. Navarra, F.C. Weise, B. Mecheri, J. Farrington, S. Licoccia, S. Greenbaum, Chem. Mater. 22 (2010) 813.

[19] F. Chen, B. Mecheri, A. D’Epifanio, E. Traversa, S. Licoccia, Fuel Cells 10 (2010) 790.

[20] J. Cejka, H.V. Bekkum, A. Corma, F. Schüth, Introduction to Zeolite Science and Practice, 3rd ed., Elsevier, Amsterdam, 2007.

[21] S.M. Auerbach, K.A. Carrado, P.K. Dutta, Handbook of Zeolite Science and Technology, Marcel Dekker Inc., New York, 2003.

[22] P. Nischwitz, P. Amels, F. Fetting Solid State Ionics 73 (1994) 105

[23] E.P. Ng, S. Mintova, Micropor. Mesopor. Mater. 114 (2008) 1.

[24] J. Kornatowski, Adsorption 11 (2005) 275.

[25] V. Tricoli, F. Nannetti, Electrochim. Acta 48 (2003) 2625.

[26] B.A. Holmberg, S.-J. Hwang, M.E. Davis, Y. Yan, Micropor. Mesopor. Mater. 80 (2005) 347.

[27] Z. Poltarzewski, W. Wieczorek, J. Przyluski, V. Antonucci, Solid State Ionics 119 (1999) 301.

[28] B. Libby, W.H. Smyrl, E.L. Cussler, AIChE J. 49 (2003) 991.

[29] T. Sancho, J. Soler, M.P. Pina, J. Power Sources 169 (2007) 92.

[30] V. Baglio, A.S. Arico, A. Di Blasi, P.L. Antonucci, F. Nannetti, V. Tricoli, V. Antonucci, J. Appl. Electrochem. 35 (2005) 207.

[31] Z. Chen, B. Holmberg, W. Li, X. Wang, W. Deng, R. Munoz, Y. Yan, Chem. Mater. 18 (2006) 5669.

[32] B.A. Holmberg, X. Wang, Y. Yan, J. Membr. Sci. 320 (2008) 86

[33] P. Kongkachuichay, S. Pimprom, Chem. Eng. Res. Des. 88 (2010) 496

[34] Y. Tao, H. Kanoh, L. Abrams, K. Kaneko, Chem. Rev. 106 (2006) 896.

[35] I. Daems, P. Leflaive, A. Methivier, G.V. Baron, J.F.M. Denayer, Micropor. Mesopor. Mater. 96 (2006) 149.

[36] H. Garcia, H.D. Roth, Chem. Rev. 102 (2002) 3947.

[37] Y. Sone, P. Ekdunge, D. Simonsson, J. Electrochem. Soc. 143 (1996) 1254.

[38] S. Slade, S.A. Campbell, T.R. Ralph, F.C. Walsh, J. Electrochem. Soc. 149 (2002) A1556.
[39] S.D. Mikhailenko, S. Kaliaguine, E. Ghali, Micropor. Mater. 11 (1997) 37.

[40] A.L. Blumenfeld, J.J. Fripiat, Magn. Reson. Chem. 37 (1999) S118.

[41] I.D. Stefanithis, K.A. Mauritz, Macromolecules 23 (1990) 2397.

[42] Q. Deng, R.B. Moore, K.A. Mauritz, J. Appl. Polym. Sci. 68 (1998) 747.

[43] V. Di Noto, R. Gliubizzi, E. Negro, G. Pace, J. Phys. Chem. B 110 (2006) 24972.

[44] L. Sun, J.S. Thrasher, Polym. Degrad. Stab. 89 (2005) 43.

[45] H. Park, Y. Kim, Y.S. Choi, W.H. Hong, D. Jung, J. Power Sources 178 (2008) 610.

[46] S. de Almeida, Y. Kawano, J. Therm. Anal. Calorim. 58 (1999) 569.

[47] Y. Iwai, T. Yamanishi, Polym. Degrad. Stab. 94 (2009) 679.

[48] Q. Deng, C.A. Wilkie, R.B. Moore, K.A. Mauritz, Polymer 39 (1998) 5961.

[49] A. Collier, H. Wang, X. Yuan, J. Zhang, D.P. Wilkinson, Int. J. Hydrogen Energy 31 (2006) 1838.

[50] S. Tan, D. Belanger, J. Phys. Chem. B 109 (2005) 23480.

[51] M. Schulze, M. Lorenz, N. Wagner, E. Gülzow, Fresenius J. Anal. Chem. 365 (1999) 106.

[52] G. Blanco-Brieva, J.M. Campos-Martin, M.P. de Frutos, J.L.G. Fierro, Ind. Eng. Chem. Res. 47 (2008) 8005.

[53] K.-D. Kreuer, A. Rabenau, W. Weppner, Angew. Chem. Int. Ed. Engl. 21 (1982) 208.

[54] A. Siu, J. Schmeisser, S. Holdcroft, J. Phys. Chem. B 110 (2006) 6072.

[55] T.L. Kalapos, B. Decker, H.A. Every, H. Ghassemi, T.A. Zawodzinski Jr., J. Power Sources 172 (2007) 14

[56] Z.H. Ping, Q.T. Nguyen, S.M. Chen, J.Q. Zhou, Y.D. Ding, Polymer 42 (2001) 8461.

[57] E. Quartarone, P. Mustarelli, A. Magistris, Solid State Ionics 110 (1998) 1

[58] C.L. Gardner, A.V. Anantaraman, J. Electroanal. Chem. 449 (1998) 209.

[59] C.L. Gardner, A.V. Anantaraman, J. Electroanal. Chem. 395 (1995) 67.

[60] K.M. Cable, K.A. Mauritz, R.B. Moore, Chem. Mater. 7 (1995) 1601.

[61] K.A. Mauritz, R.B. Moore, Chem. Rev. 104 (2004) 4535.

[62] Y.A. Elabd, C.W. Walker, F.L. Beyer, J. Membr. Sci. 231 (2004) 181.

[63] O. Yamada, Y. Yin, K. Tanaka, H. Kita, K. Okamoto, Electrochim. Acta 50 (2005) 2655.

[64] S. Ma, Z. Siroma, H. Tanaka, J. Electrochem. Soc. 153 (2006) A2274.

[65] T. Soboleva, Z. Xie, Z. Shi, E. Tsang, T. Navessin, S. Holdcroft, J. Electroanal. Chem. 622 (2008) 145

[66] A.S. Arico, S. Srinivasan, V. Antonucci, Fuel Cells 1 (2001) 133.

[67] V. Baglio, A. Di Blasi, E. Modica, P. Creti, V. Antonucci, A.S. Arico, J. New Mater. Electrochem. Syst. 9 (2006) 41

[68] A. Heinzel, V.M. Barragan, J. Power Sources 84 (1999) 70.

[69] J. Ge, H. Liu, J. Power Sources 142 (2005) 56.

[70] L. Chaabane, G. Bulvestre, C. Larchet, V. Nikonenko, C. Deslouis, H. Takenouti, J. Membr. Sci. 323 (2008) 167. 